University of Tennessee Health Science Center

UTHSC Digital Commons

\title{
The Cystic Fibrosis Transmembrane Conductance Regulator: Regulation by HSP-90
}

\author{
Kevin Marrs \\ University of Tennessee Health Science Center
}

Follow this and additional works at: https://dc.uthsc.edu/dissertations

Part of the Congenital, Hereditary, and Neonatal Diseases and Abnormalities Commons

\section{Recommended Citation}

Marrs, Kevin , "The Cystic Fibrosis Transmembrane Conductance Regulator: Regulation by HSP-90" (2007). Theses and Dissertations (ETD). Paper 162. http://dx.doi.org/10.21007/etd.cghs.2007.0202.

This Dissertation is brought to you for free and open access by the College of Graduate Health Sciences at UTHSC Digital Commons. It has been accepted for inclusion in Theses and Dissertations (ETD) by an authorized administrator of UTHSC Digital Commons. For more information, please contact jwelch30@uthsc.edu. 


\title{
The Cystic Fibrosis Transmembrane Conductance Regulator: Regulation by HSP-90
}

\begin{abstract}
The hypothesis of this project is that a functionally relevant association exists between CFTR and Hsp90. In testing this hypothesis, (a) the association of CFTR and Hsp90 is confirmed via crosslinking and immunoprecipitation of CFTR from stably transfected HEK-293 cells, electrophoretic separation of crosslinked proteins, and protein identification via SDS-PAGE, western blotting, and mass spectrometry. Also, this hypothesis is tested by (b) functionally assessing the effect of Hsp90 on CFTR function via Ussing chamber analysis, two-electrode voltage clamp analysis, preliminary in vivoanimal studies, and protein phosphorylation. The HEK-293 Flag-CFTR cells used in this study allows for a high degree of protein purification in quantities sufficient for mass spectroscopy, which has not been possible in other cell lines. An approximately $170 \mathrm{kDa}$ band could be detected with CFTR specific antibodies. The HEK-293 Flag-CFTR cells also show increased protein expression levels above that observed in BHK cells transfected with wild-type (WT)-CFTR and CFTRhis10. The Flag-CFTR expression was not only confirmed via immunofluorescent detection, but was also shown to be functional using a standard iodide efflux assay. The HEK-293 Flag-CFTR cells responded to agonists known to activate CFTR (forskolin, IBMX, cpt.cAMP, isoproterenol, and adenosine). Furthermore, these cells express sufficient quantities of protein to allow for mass spectrometric analysis, which has proven difficult in other cell lines. Thus, this cell line is a valuable tool for the biochemical and functional characterization of CFTR and should prove useful for future studies assessing protein-protein interactions as they relate to CFTR. Using cross-linking reagents (DSP \& DPDPB), Hsp-90 is shown to be in association with CFTR in stably transfected HEK-293 cells. Hsp90 associates with CFTR under these conditions more prominently than does Hsp70. The amount of Hsp90 in the macromolecular complex with CFTR is sufficient for mass spectrometry identification. An in vitro assay for CFTR transport function (Ussing Chamber) shows that inhibition of Hsp90 with RD, an

Hsp90 inhibitor with nanomolar affinity, decreases CFTR mediated $\mathrm{Cl}^{-}$transport. Preliminary in vivo airway fluid clearance studies in mice also show that RD inhibits fluid transport, known to require CFTR. Also, Hsp90 protein increases the two-electrode voltage clamp current measured from Xenopus oocytes expressing CFTR chloride channels. When assessing the phosphorylation status of CFTR, it is seen that under conditions that increase the association of Hsp90, there is also observed an increase in the phosphorylation of CFTR. Conversely, in the presence of increasing concentrations of RD, both the Hsp90 association CFTR and the phosphorylation of CFTR tend to decrease. Taken together these data suggest that Hsp90 can be positively identified in complex with CFTR and can functionally regulate its activity.
\end{abstract}

Document Type

Dissertation

Degree Name

Doctor of Philosophy (PhD)

Program

Biomedical Sciences

Research Advisor

Anjaparavanda Naren, Ph.D.

Keywords

CFTR, cystic fibrosis transmembrane conductance regulator, Hsp90, PKA, Mass Spectrometry, Xenopus, 
Calu-3, HEK-293, Radicicol, Ussing Chamber

\section{Subject Categories}

Congenital, Hereditary, and Neonatal Diseases and Abnormalities | Diseases | Medicine and Health Sciences 


\title{
The Cystic Fibrosis Transmembrane Conductance Regulator:
} Regulation by HSP-90

\author{
A Dissertation \\ Presented for \\ The Graduate Studies Council \\ The University of Tennessee \\ Health Science Center
}

\author{
In Partial Fulfillment \\ Of the Requirements for the Degree \\ Doctor of Philosophy \\ From The University of Tennessee
}

By

Kevin L. Marrs

December, 2007 
Copyright (C), 2007 by Kevin L. Marrs All rights reserved 


\section{DEDICATION}

This dissertation is dedicated to A.P. Naren, and Leonard R. Johnson, and LCDR Jimmy Ryals for opening the door to this wonderful opportunity. 


\section{ACKNOWLEDGEMENTS}

I acknowledge with gratitude the assistance of my Research Advisor, A.P. Naren, rendered continually throughout the duration of my graduate training. This work would not have been possible without the motivation, direction and assistance he continually provided. I thank my committee members Suleiman Bahouth, Lawrence Pfeffer, R.K. Rao, and Donald Thomason for their valuable feedback on my research project. I'd also like members of the Naren Lab, Chunying Li and Bindu Penmatsa, for their advice, technical assistance, and support. I'd like to thank Edward Umstot, Parimal Seth, the UTHSC and UAB Mass Spectrometry Core Laboratories their assistance with Mass Spectrometry experiments. I'd also like to acknowledge the assistance rendered by Nael McCarty of the Georgia Institute of Technology for assistance with the two-electrode voltage clamping technique. Also, I'd like to thank Jeetendra Eswaraka as well as the Dopico Laboratory, particularly Alex Dopico, Maria Asuncion-Chin and Anna Bukiya for their assistance with the experimental preparation of Xenopus Oocytes. Phillip Factor of Columbia was most helpful in assisting with airway fluid clearance measurements. And, I am most appreciative of the generosity of Dr. K.U. Malik for allowing this work to be funded through the NIH-Training Grant "Lipid / Lipoprotein Metabolism and Cardiovascular Diseases". Also, I thank Shirley Hancock and David Armbruster for their assistance with preparing the final version of this dissertation. And last, but certainly not least of all, I would like to thank my wife Jessica for all of her loving support and wisdom offered through this process. Likewise, I thank my children Sarah Katherine, Natalie, and Elizabeth for their loving patience with Dad's time away from home. I also 
gratefully appreciate the support of my parents, Robert and Dana Marrs, as well as my

mother-in-law and father-in -law, Harry and Jeanne Shirley. This work has been assisted and made possible through the generosity and support of these individuals. 


\begin{abstract}
The hypothesis of this project is that a functionally relevant association exists between CFTR and Hsp90. In testing this hypothesis, (a) the association of CFTR and Hsp90 is confirmed via crosslinking and immunoprecipitation of CFTR from stably transfected HEK-293 cells, electrophoretic separation of cross-linked proteins, and protein identification via SDS-PAGE, western blotting, and mass spectrometry. Also, this hypothesis is tested by (b) functionally assessing the effect of Hsp90 on CFTR function via Ussing chamber analysis, two-electrode voltage clamp analysis, preliminary in vivo animal studies, and protein phosphorylation. The HEK-293 Flag-CFTR cells used in this study allows for a high degree of protein purification in quantities sufficient for mass spectroscopy, which has not been possible in other cell lines. An approximately $170 \mathrm{kDa}$ band could be detected with CFTR specific antibodies. The HEK-293 FlagCFTR cells also show increased protein expression levels above that observed in BHK cells transfected with wild-type (WT)-CFTR and CFTRhis10. The Flag-CFTR expression was not only confirmed via immunofluorescent detection, but was also shown to be functional using a standard iodide efflux assay. The HEK-293 Flag-CFTR cells responded to agonists known to activate CFTR (forskolin, IBMX, cpt.cAMP, isoproterenol, and adenosine). Furthermore, these cells express sufficient quantities of protein to allow for mass spectrometric analysis, which has proven difficult in other cell lines. Thus, this cell line is a valuable tool for the biochemical and functional characterization of CFTR and should prove useful for future studies assessing proteinprotein interactions as they relate to CFTR. Using cross-linking reagents (DSP \&
\end{abstract}


DPDPB), Hsp-90 is shown to be in association with CFTR in stably transfected HEK-293 cells. Hsp90 associates with CFTR under these conditions more prominently than does Hsp70. The amount of Hsp90 in the macromolecular complex with CFTR is sufficient for mass spectrometry identification. An in vitro assay for CFTR transport function (Ussing Chamber) shows that inhibition of Hsp90 with RD, an Hsp90 inhibitor with nanomolar affinity, decreases CFTR mediated $\mathrm{Cl}^{-}$transport. Preliminary in vivo airway fluid clearance studies in mice also show that RD inhibits fluid transport, known to require CFTR. Also, Hsp90 protein increases the two-electrode voltage clamp current measured from Xenopus oocytes expressing CFTR chloride channels. When assessing the phosphorylation status of CFTR, it is seen that under conditions that increase the association of Hsp90, there is also observed an increase in the phosphorylation of CFTR. Conversely, in the presence of increasing concentrations of $\mathrm{RD}$, both the Hsp90 association CFTR and the phosphorylation of CFTR tend to decrease. Taken together these data suggest that Hsp90 can be positively identified in complex with CFTR and can functionally regulate its activity. 


\section{TABLE OF CONTENTS}

CHAPTER 1: GENERAL INTRODUCTION.................................................................. 1

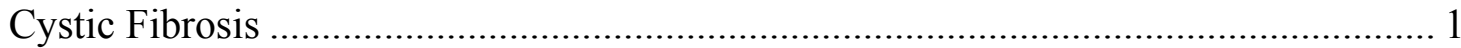

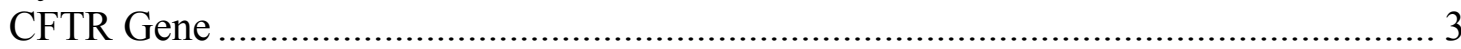

CFTR Cell Biology ............................................................................................ 5

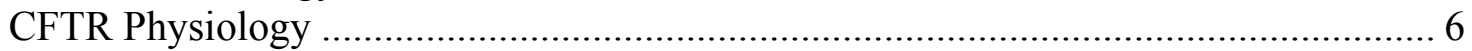

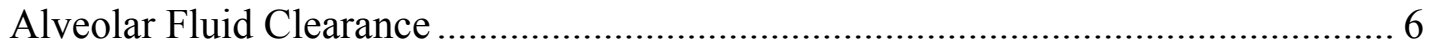

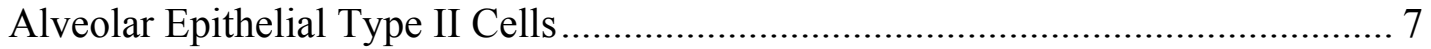

Alveolar Epithelial Type I Cells ....................................................................... 8

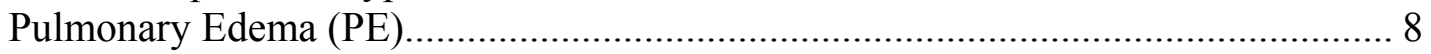

Acute Lung Injury (ALI) ......................................................................... 11

Pulmonary Edema, Acute Lung Injury, and Alveolar Fluid Clearance.................... 12

CFTR, the Epithelial Sodium Channel (ENaC), and the Beta -2 Adrenergic Receptor

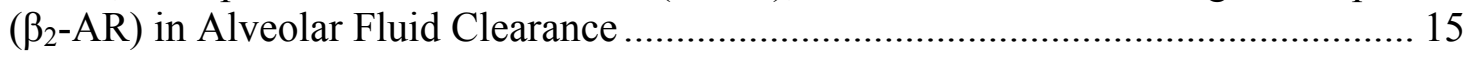

CFTR Interacting Partners ................................................................................ 18

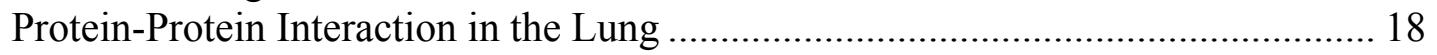

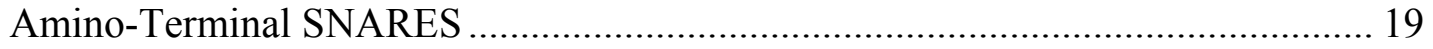

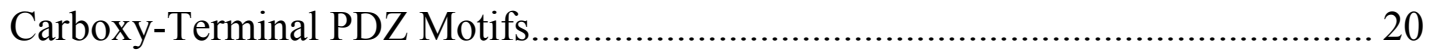

Nucleotide Binding Domains (NBDs) - Scaffolding Proteins ............................... 21

Hsp90 and Chloride Channel Regulation ......................................................... 21

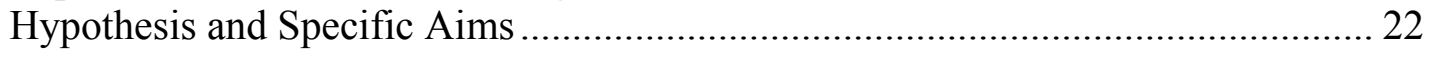

\section{CHAPTER 2: PURIFICATION OF FLAG-CFTR FROM HEK-293 CELLS ....... 24}

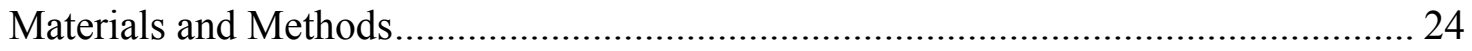

Generation of HEK-Flag-CFTR Cell Line ......................................................... 24

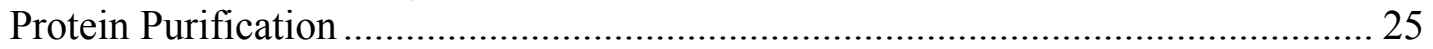

Purification of the Cross-Linked Macromolecular Complex................................ 25

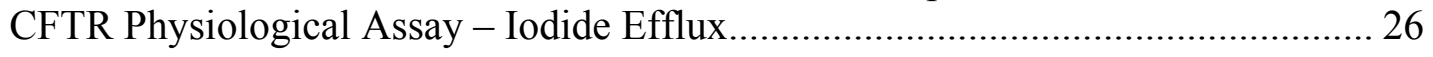

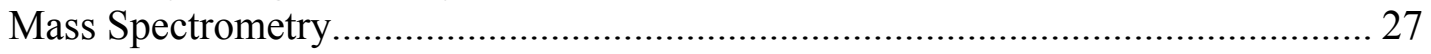

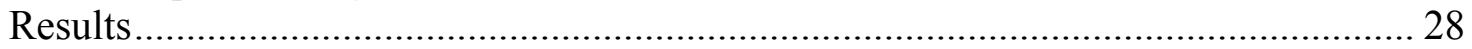

Purification of CFTR (Microgram Quantities) .................................................... 28

Flag-CFTR Cell Line Functional Assay ........................................................... 31

Mass Spectrophotometric Identification of CFTR .......................................... 35

\section{CHAPTER 3: HSP-90 AND CFTR: ASSOCIATION AND FUNCTIONAL}

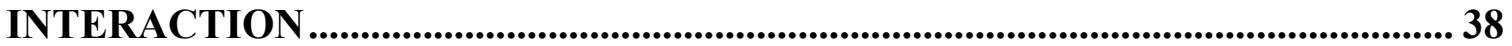

Materials and Methods..................................................................................... 38

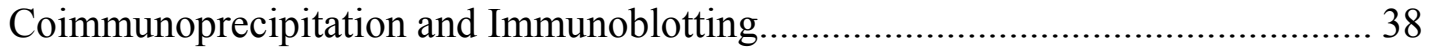

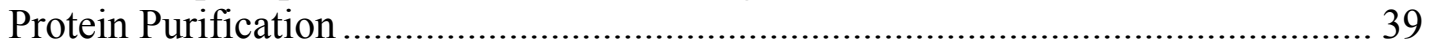

Short-Circuit Current Assay ............................................................................... 39 


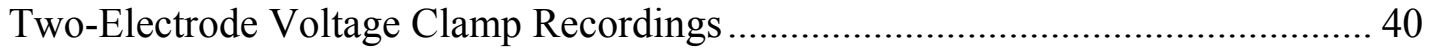

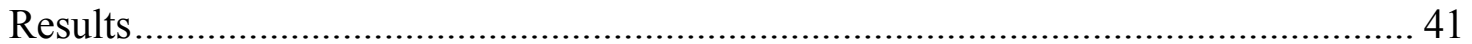

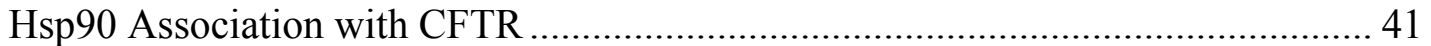

Hsp90 Mass Spectrometry ................................................................................. 46

Hsp90 Augmentation of CFTR Chloride Transport ............................................... 46

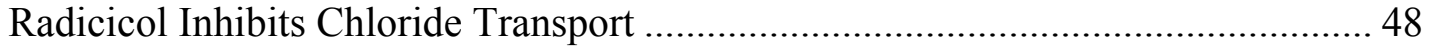

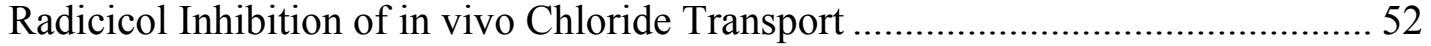

Hsp90 Association Increases CFTR Phosphorylation ....................................... 55

Radicicol Inhibits CFTR Phosphorylation.......................................................... 55

CHAPTER 4: GENERAL DISCUSSION ..........................................................60

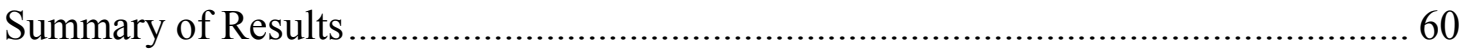

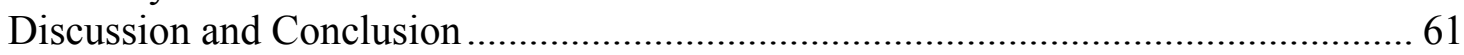

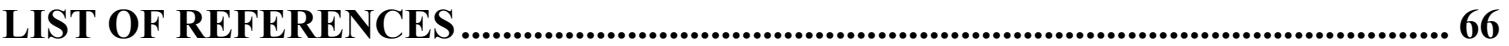

VITA 


\section{LIST OF FIGURES}

Figure 1-1. The Cystic Fibrosis Transmembrane Conductance Regulator (CFTR) .......4

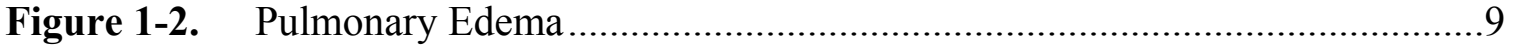

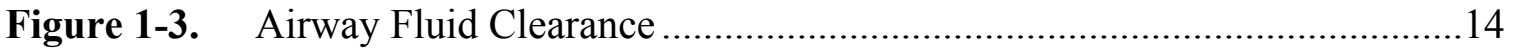

Figure 1-4. Role of CFTR in Airway Fluid Clearance ............................................... 17

Figure 2-1. Flag-CFTR ....................................................................................29

Figure 2-2. HEK-Flag-CFTR Cells Express Detectable CFTR.....................................

Figure 2-3. HEK-Flag-CFTR and BHK Cell Expression of CFTR............................32

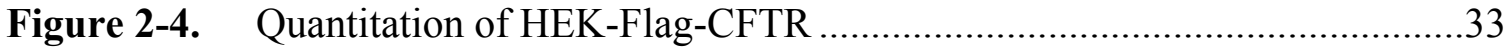

Figure 2-5. HEK-293-Flag-CFTR Cells Respond to CFTR Activating Agonists........35

Figure 2-6. Purification of Flag-CFTR ...................................................................36

Figure 2-7. Mass Spectrometry: Identification of Flag-CFTR ................................37

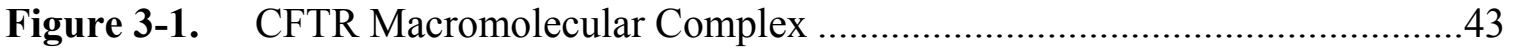

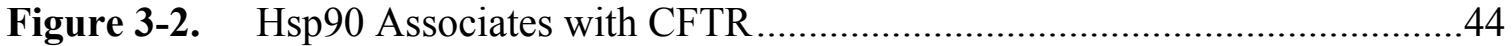

Figure 3-3. Hsp-90 Specific Association with CFTR ................................................46

Figure 3-4. Mass Spectrometry: Identification of Hsp90 .........................................48

Figure 3-5. Expression of CFTR cRNA in Xenopus Oocytes...................................49

Figure 3-6. Inhibition of CFTR in Xenopus Oocytes by DPC …..............................50

Figure 3-7. HSP-90 Increases CFTR Conductance in Xenopus Oocytes.....................51

Figure 3-8. Radicicol Inhibits CFTR-Mediated Short-Circuit Currents $\left(\mathrm{I}_{\mathrm{sc}}\right)$..............53

Figure 3-9. Radicicol Inhibits in vivo Airway Fluid Transport in C57BL/6 Mice.......55

Figure 3-10. Phospho-PKA Substrate Antibody Recognizes CFTR ...........................56

Figure 3-11. Hsp90 Association Increases CFTR Phosphorylation .............................58

Figure 3-12. Radicicol Inhibits CFTR Association with Hsp90 and CFTR Phosphorylation ........................................................................59

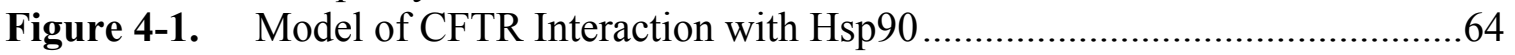




\section{LIST OF ABBREVIATIONS}

$\alpha$

$\AA$

$\mathrm{ABC}$

AFM

AKAP

ALI

AR

ARDS

AT1

AT2

ATP

$\beta$

$\beta$-AR

$\beta_{2}-\mathrm{AR}$

BHK

BSA

C

${ }^{\mathrm{o}} \mathrm{C}$

$\mathrm{Ca}^{2+}$

Calu-3

cAMP alpha

angstrom

ATP binding cassette

atomic force microscopy

A-kinase-anchoring proteins

acute lung injury

adrenergic receptor

acute respiratory distress syndrome

alveolar epithelial cells type I

alveolar epithelial cells type II

adenosine triphosphate

beta

$\beta$-adrenergic receptors

$\beta_{2}$-adrenergic receptors

baby-hamster kidney

bovine serum albumin

carboxyl

degrees Celsius

calcium

human, caucasian, lung, adenocarcinoma

adenosine-3',5'-cyclic monophosphate 


\begin{tabular}{|c|c|}
\hline CAP70 & cftr-associated protein - $70 \mathrm{kDa}$ \\
\hline $\mathrm{CF}$ & cystic fibrosis \\
\hline CFTR & cystic fibrosis transmembrane conductance regulator \\
\hline $\mathrm{Cl}^{-}$ & chloride \\
\hline cPKA & catalytic subunit of PKA \\
\hline cpt.cAMP & 8-(4-chlorophenylthio) adenosine-3',5'-cyclic monophosphate \\
\hline cRNA & complementary ribonucleic acid \\
\hline $\mathrm{D}$ & aspartic acid \\
\hline $\mathrm{Dlg} A$ & drosophila disc large tumor suppressor \\
\hline DPC & diphenylamine carboxylate \\
\hline DPDPB & 1,4-di-[3'-(2'-pyridyldithio)-propionamido]butane \\
\hline DSP & dithiobis(succinimidyl)propionate \\
\hline DTBP & dimethyl $3,3^{\prime}$-dithiobispropionimidate $\cdot 2 \mathrm{HCl}$ \\
\hline EBP50 & ERM binding phosphoprotein of $50 \mathrm{kDa}$ \\
\hline $\mathrm{ENaC}$ & epithelial sodium channel \\
\hline ERM & ezrin, radixin, moesin \\
\hline ESI & electrospray-ionization \\
\hline $\mathrm{H}^{+}$ & hydrogen \\
\hline $\mathrm{HCl}$ & hydrochloride \\
\hline $\mathrm{HCO}_{3}^{-}$ & bicarbonate \\
\hline HEK-293 & human embryonic kidney - 293 \\
\hline HEPES & 4-(2-hydroxyethyl)-1-piperazineethanesulfonic acid \\
\hline $\mathrm{Hg}$ & mercury \\
\hline
\end{tabular}




\begin{tabular}{|c|c|}
\hline HSP & heat shock protein \\
\hline $\mathrm{Hz}$ & hertz \\
\hline IBMX & 3-Isobutyl-1-methylxanthine \\
\hline $\mathrm{I}-\mathrm{V}$ & current-voltage \\
\hline $\mathrm{KCl}$ & potassium chloride \\
\hline $\mathrm{L}$ & leucine \\
\hline $\mathrm{LC}$ & liquid chromatography \\
\hline LLCPK1 & Porcine kidney epithelial cells \\
\hline M & molar \\
\hline MALDI & Matrix Assisted Laser Desorption/Ionization \\
\hline MDCK & Madin-Darby canine kidney \\
\hline MDR & multidrug resistance \\
\hline ME & mercaptoethanol \\
\hline $\mathrm{mg}$ & milligram \\
\hline $\mathrm{MgCl}$ & magnesium chloride \\
\hline $\min$ & minute \\
\hline $\mathrm{ml}$ & milliliter \\
\hline $\mathrm{mm}$ & millimeter \\
\hline $\mathrm{mM}$ & millimolar \\
\hline MOhms & mega ohms \\
\hline MS & mass spectrometry \\
\hline $\mathrm{ms}$ & millisecond \\
\hline $\mathrm{mV}$ & millivolts \\
\hline
\end{tabular}




\begin{tabular}{|c|c|}
\hline $\mathrm{Na}^{+}$ & sodium \\
\hline $\mathrm{Na}^{+} / \mathrm{K}^{+}$ATPase & sodium potassium ATPase \\
\hline $\mathrm{NaNO}_{3}$ & sodium nitrate \\
\hline NBD & nucleotide binding domain \\
\hline ND96 & oocyte recording solution \\
\hline ng & nanograms \\
\hline NHERF & $\mathrm{Na}+/ \mathrm{H}+$ exchanger regulatory factor \\
\hline $\mathrm{nL}$ & nanoliter \\
\hline NSF & n-ethylmaleimide-sensitive fusion \\
\hline $\mathrm{P}$ & probability \\
\hline PAGE & polyacralymide gel electrophoresis \\
\hline PDZ & PSD95/DlgA/zo-1 \\
\hline PE & pulmonary edema \\
\hline PKA & protein kinase $\mathrm{A}$ \\
\hline $\mathrm{pS}$ & picosiemens \\
\hline PSD95 & post synaptic density protein \\
\hline PVDF & polyvinylidene difluoride \\
\hline QIT & quadrupole ion trap \\
\hline $\mathrm{R}$ & arginine \\
\hline $\mathrm{RD}$ & radicicol \\
\hline RIPA & radioimmunoprecipitation \\
\hline ROMK & renal epithelial cell potassium channels \\
\hline RT-PCR & reverse transcription polymerase chain reaction \\
\hline
\end{tabular}




$\begin{array}{ll}\text { SD } & \text { standard deviation } \\ \text { SDS } & \text { sodium dodecyl sulfate } \\ \text { SEM } & \text { standard error of the mean } \\ \text { SNAP-23 } & \text { soluble NSF attachment protein of } 23 \text { kilodaltons } \\ \text { T } & \text { threonine } \\ \text { TBS } & \text { tris-base saline } \\ \text { TFA } & \text { trifluoroacetic acid } \\ \text { TOF } & \text { Time-of-Flight } \\ \text { t-SNARES } & \text { target soluble NSF attachment protein receptors } \\ \text { TX-100 } & \text { triton-X-100 } \\ \mu \mathrm{g} & \text { microgram } \\ \mu \mathrm{M} & \text { micromolar } \\ \text { wt } & \text { wild-type } \\ \text { ZO-1 } & \text { zonula occuldens-1 protein }\end{array}$




\section{CHAPTER 1: GENERAL INTRODUCTION}

\section{Cystic Fibrosis}

Cystic fibrosis (CF) is the most common genetic disease affecting Caucasians. The disease affects approximately 1 in 2,000 to 3,000 live births (Boat, Welsh et al. 2001). Anderson published the first comprehensive description of CF in 1938, wherein the term "cystic fibrosis of the pancreas" was coined (Anderson 1938). Soon thereafter in 1945, it was suggested by Farber that CF is an exocrine gland disease predominately characterized by an inability to clear mucus secretions. He introduced the term mucoviscidosis, by which the disease is also known (Farber 1945). In 1949, Lowe et al. proposed, based on an autosomal recessive pattern of inheritance, that CF must be caused by a defect in a single gene (Lowe, May et al. 1949; Rowe, Miller et al. 2005).

Clinically, it was observed that the organs affected by CF such as sweat glands, airways, pancreas, salivary glands, epididymis, and intestine were all epithelial tissue containing organs. Also, it was noted that the glands of these organs were obstructed by abnormally thick and dehydrated secretions (Boat, Welsh et al. 2001).

In the lung, mucous obstruction and infection are the major pathologic events. It is likely that mucus obstruction is primary pathophysiological event. Failure to clear secretions most likely provides an environment that is conducive to the establishment of chronic infection, leading to destruction of the respiratory tract (Boat, Welsh et al. 2001). The average age of death in CF patients, which is caused by respiratory insufficiency, is approximately 37 years of age (Davis 2006). CF patients may predominantly have symptoms related to the gastrointestional tract. Newborns with CF have meconium ileus 
in $10 \%-20 \%$ of the cases. This has been ascribed to inadequate pancreatic enzyme secretion. However, it has also been suggested that the causal event may be dehydration of the contents of the intestine due to defective epithelial transport. With proper treatment, GI abnormalities are rarely life-threatening (Boat, Welsh et al. 2001).

The great majority of patients with CF have exocrine pancreatic insufficiency from birth. Occasionally in childhood, loss of pancreatic function is observed followed by pancreatitis. In almost all cases the pancreas is abnormal and, upon autopsy, is observed to be virtually destroyed (di Sant' Agnese and Hubbard 1984; Atlas, Orenstein et al. 1992; Boat, Welsh et al. 2001). In male patients with CF, more than 95 percent have altered Wolffian duct structures. Fibrosis, atrophy, or complete absence of the vas deferens, epididymis and seminal vesicles is observed (Taussig, Lobeck et al. 1972; Boat, Welsh et al. 2001).

In the early 1980's, two groups published work establishing that the hallmark of CF epithelia is defective chloride $\left(\mathrm{Cl}^{-}\right)$transport. First, in 1981, abnormalities in chloride and sodium transport in CF epithelia was described by Knowles and colleagues (Knowles, Gatzy et al. 1981). Then, in 1983, chloride impermeability of the CF sweat ducts was demonstrated by Quinton and Bijman (Quinton and Bijman 1983).

Elevated sweat chloride concentrations are the most consistent functional alteration in CF patients. This is not due to an increase in the number of sweat glands (Boat, Welsh et al. 2001). Quinton demonstrated that the sweat gland pathophysiology is due to failure of the gland to reabsorb chloride along the duct (Quinton 1986). Interestingly, European folklore makes reference to an association between salty skin of infants and an early mortality (Taussig 1984). Current diagnosis of CF is still based in 
part upon sweat chloride levels combined with clinical criteria. The clinical features used for diagnosis are typical pulmonary manifestation, typical gastrointestinal manifestations, and genetics (i.e., a history of $\mathrm{CF}$ in the immediate family). Any one of these features combined with a sweat chloride level $>60 \mathrm{meq} / \mathrm{liter}$ (normal $=10-35 \mathrm{meq} / \mathrm{liter}$ ) or with pathologic mutations on both chromosomes is sufficient to make a diagnosis for CF (Boat, Welsh et al. 2001).

\section{CFTR Gene}

The defective gene responsible for CF was identified by Collins, Rirodan, Tsui, and colleagues (Kerem, Rommens et al. 1989; Riordan, Rommens et al. 1989; Rommens, Iannuzzi et al. 1989). Based upon the sequence of the CFTR gene, it was correctly predicted to be a member of the ATP Binding Cassette (ABC) Transporter super family of proteins (Figure 1-1). Like other ABC transporters, CFTR has 2 Nucleotide binding domains (NBDs), and 12 membrane-spanning alpha helixes. $\mathrm{ABC}$ transporters include genes that are known to transport organic solutes such as multidrug resistance (MDRs, or

P-glycoprotein) genes, and a number of small nutrient and molecular transporters in both prokaryotic and eukaryotic systems (Borst and Elferink 2002). The CFTR product encodes for a chloride channel. When it was determined to be an $\mathrm{ABC}$ transporter with several consensus sites for protein kinase A (PKA) phosphorylation, it was suggested that the gene product may serve to transport out of the cell a cytoplasmic inhibitor of another chloride channel responsible for CF. Thus, the name Cystic Fibrosis transmembrane Conductance Regulator (CFTR) was given (Riordan, Rommens et al. 1989; (Riordan, Rommens et al. 1989; Gadsby, Vergani et al. 2006). However, CFTR was soon 


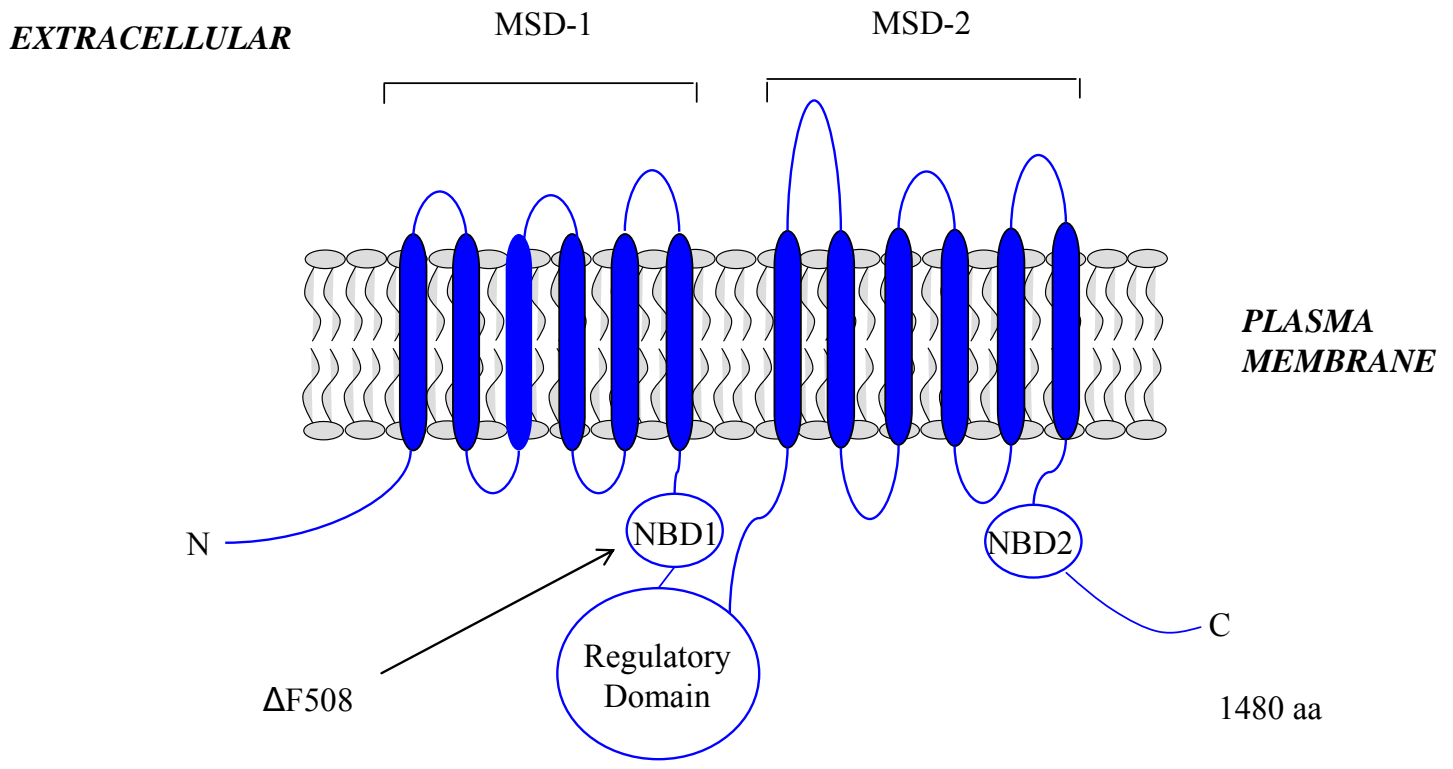

INTRACELLULAR

$$
\begin{aligned}
\text { MSD }= & \text { membrane spanning domain } \\
\text { NBD }= & \text { nucleotide binding domain } \\
\Delta \mathrm{F} 508= & \text { deletion of phenylalanine at amino } \\
& \text { acid position } 508
\end{aligned}
$$

Figure 1-1. The Cystic Fibrosis Transmembrane Conductance Regulator (CFTR) 
determined to hold a unique place among the $\mathrm{ABC}$ transporter. Studies have confirmed that it does in fact serve as a chloride ion channel. CFTR is activated directly by PKA phosphorylation. The channel allows chloride ions to flow equally well in either direction at a conduce rate of $\leq 10 \mathrm{pS}$ (Bear, Li et al. 1992).

\section{CFTR Cell Biology}

CFTR protein expression in bronchial tissue from non-CF individuals is primarily found in submucosal glands (specifically, the serous component of the secretory tubules and a subpopulation of duct cells) (Engelhardt, Yankaskas et al. 1992). CFTR is an apical membrane protein (Denning, Ostedgaard et al. 1992). CFTR is present in the apical membrane of proximal (centroacinar and intralobar) duct epithelial cells with no conclusive staining in acinar cells (Marino, Matovcik et al. 1991). CFTR is also present in the distal and alveolar airway epithelia (Engelhardt, Zepeda et al. 1994). It functions in the transport of salt and water and is regulated by cAMP (Quinton and Bijman 1983; Anderson, Gregory et al. 1991; Bear, Li et al. 1992). CFTR has also been demonstrated to regulate the activity of other channels and transporters including the epithelial sodium $\left(\mathrm{Na}^{+}\right)$channel (ENaC) (Knowles, Stutts et al. 1983; Boucher, Stutts et

al. 1986; Stutts, Canessa et al. 1995), renal epithelial cell potassium channels ROMK1 and ROMK2 (McNicholas, Guggino et al. 1996; McNicholas, Nason et al. 1997; Cahill, Nason et al. 2000), aquaporin water channel (Schreiber, Nitschke et al. 1999), and $\mathrm{Cl}^{-} / \mathrm{HCO}_{3}{ }^{-}$exchangers (Lee, Wigley et al. 1999; Lohi, Lamprecht et al. 2003).

At the time of writing, over 1500 mutations have been identified. These mutations are divided into 5 general classes (Zielenski and Tsui 1995). The $\Delta \mathrm{F} 508$ - 
CFTR mutation, which corresponds to a deletion of three base pairs, results in a loss of the amino acid phenylalanine at position 508 of the amino acid sequence. The $\Delta \mathrm{F} 508$ CFTR mutation accounts for approximately 70 percent of the mutations in patients with cystic fibrosis (Kerem, Rommens et al. 1989). Amino acid position 508 lies in the nucleotide binding domain 1 (NBD-1) of CFTR (Thomas, Shenbagamurthi et al. 1992). $\Delta$ F508-CFTR mutation results in only core glycosylation of CFTR, due to the protein being trapped in intracellular compartments as a result of defective intracellular trafficking (Cheng, Gregory et al. 1990; Denning, Anderson et al. 1992; Du, Sharma et al. 2005). The processing defect of $\Delta \mathrm{F} 508$-CFTR cells can be corrected in vitro. When the temperature is reduced to $28-30{ }^{\circ} \mathrm{C}$, cAMP-regulated $\mathrm{Cl}^{-}$channels appear in the plasma membrane and $\mathrm{Cl}^{-}$transport is restored (Denning, Anderson et al. 1992). $\Delta \mathrm{F} 508$-CFTR that happens to be present in the plasma membrane has a reduced half-life when compared to wild-type CFTR (Lukacs, Chang et al. 1993). It has been shown that ubiquitination of CFTR leads to rapid degradation (Ward, Omura et al. 1995).

\section{CFTR Physiology}

\section{Alveolar Fluid Clearance}

The general model for airway fluid clearance is that transepithelial fluid movement is driven by active salt transport which in turn drives osmotic water movement (Matthay, Folkesson et al. 2002; Matthay, Robriquet et al. 2005). The alveolar epithelium comprises $99 \%$ of the lung surface area. The barrier created by the alveolar epithelium and the capillaries under normal conditions has a low solute permeability. 
The alveolar epithelium provides most of the resistance to plasma proteins due to the higher reflection coefficient for proteins (i.e., decreased permeability) compared to the capillary epithelium. Yet, it is the primary site for the removal of excess alveolar fluid. The major driving force for water reabsorption is the osmotic gradient created by active $\mathrm{Na}^{+}$ion transport with a confirmed role for the transport of $\mathrm{Cl}^{-}$ions as well.

The monolayer of alveolar epithelial cells consists of a thin layer of squamous type I cells (AT1) and cuboidal type II cells (AT2) (Mutlu and Sznajder 2005).

\section{Alveolar Epithelial Type II Cells}

Because type II cells can be readily isolated and studied in vitro, they have been more extensively studied compared to type I cells. The cuboidal type II cells have a diameter of approximately $10 \mu \mathrm{M}$ and are the site responsible for the secretion of surfactant. Also, a major driving force for the removal of fluid from the alveolar space is provided by active sodium and chloride transport from type II cells. Sodium enters the cells through apical sodium channels (amiloride-sensitive and amiloride-insensitive) and CFTR may represent a rate-limiting step for salt transport by these cells (see below for discussion). The sodium that enters the cells apically is extruded from the cells via the basolateral $\mathrm{Na}^{+} / \mathrm{K}^{+}$-ATPase. This mechanism allows alveolar lung fluid to be cleared from the airspace and returned to the lung Interstitium and pulmonary circulation (Matthay, Robriquet et al. 2005; Mutlu and Sznajder 2005; Guidot, Folkesson et al. 2006). 


\section{Alveolar Epithelial Type I Cells}

The squamous type I cells have a diameter ranging from 50 to $100 \mu \mathrm{M}$. They make up $90 \%$ of the alveolar surface (Mutlu and Sznajder 2005). It was previously thought that AT2 cells are responsible for most of the vectorial apical to basolateral $\mathrm{Na}^{+}$ transport across the alveoli. But, an important role has emerged for AT1 cells in vectorial $\mathrm{Na}^{+}$transport. Like the $\mathrm{Na}^{+} / \mathrm{K}^{+}$-ATPase, all three subunits of the epithelial $\mathrm{Na}^{+}$channel $(\mathrm{ENaC})$ has been demonstrated in AT1 cells, which contribute approximately $60 \%$ to active sodium transport. Also, of all the mammalian cells, freshly isolated AT1 cells have the greatest osmotic water permeability. This is possibly contributed by aquaporin5 (AQP-5) (see Figure 1-2) (Matthay, Robriquet et al. 2005; Mutlu and Sznajder 2005).

\section{Pulmonary Edema (PE)}

Pulmonary edema $(\mathrm{PE})$ is caused by an increased accumulation of fluid in the lung airspace and impaired function of the active $\mathrm{Na}^{+}$and $\mathrm{Cl}^{-}$transport mechanisms that normally serve to remove fluid from the alveoli (Factor, Mutlu et al. 2007). The two fundamentally different types of pulmonary edema that occur in humans are known as cardiogenic pulmonary edema and noncardiac pulmonary edema (Figure 1-2). Cardiac pulmonary edema is also known as hydrostatic or hemodynamic edema. Non-cardiac pulmonary edema is also known as increased-permeability pulmonary edema, acute lung injury, or acute respiratory distress syndrome. Cardiogenic and noncardiogenic pulmonary edema have distinct cause, yet they present similar clinical manifestations that make them difficult to distinguish (Ware and Matthay 2005). 


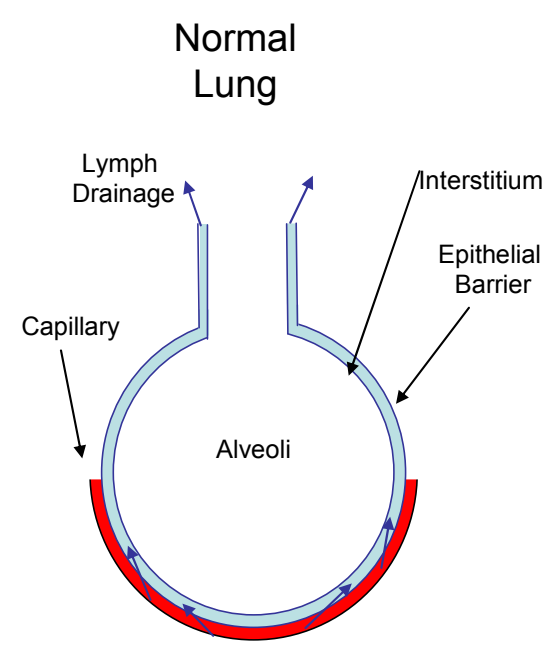

-Fluid is filtered from the capillaries across endothelium

-Moves into the interstitium

-Drains into lymphatics

\section{Cardiogenic \\ Pulmonary \\ Edema}

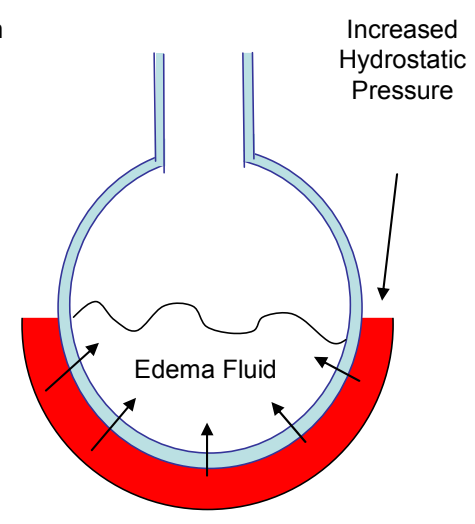

-Increased hydrostatic pressure - Fluid filtration is increased

-Alveoli are flooded by bulk flow (Aquaporins)

-Epithelial barrier is tight

-Protein-poor edema fluid

\section{Noncardiogenic \\ Pulmonary \\ Edema}

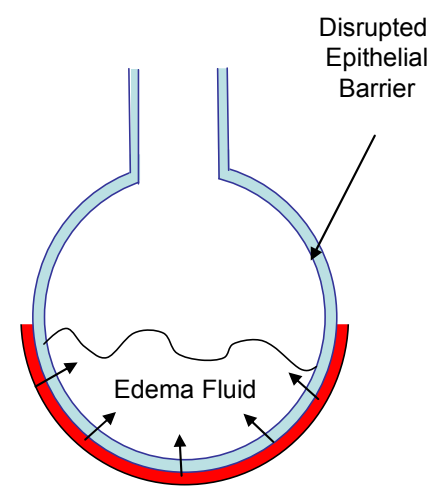

-Normal Hydrostatic Pressure -Alveolar flooding due to increased epithelial permeability -Disrupted epithelial barrier -Protein-rich edema fluid

Figure 1-2. Pulmonary Edema 
Fluid and protein leakage into the airspace of normal lungs occurs primarily through small gaps that exist between endothelial cells and capillaries. Due to the tight junctions, fluid and solutes from the circulation usually will not enter the alveoli. Fluid will typically move proximal to the alveolar space into the peribronchovascuar space. The lymphatics will then return the fluid from the interstitium to the circulation. The forces affecting fluid filtration across the lung microcirculation are derived from a combination of hydrostatic forces and protein osmotic forces. The hydrostatic force is approximately equal to the hydrostatic pressure in the pulmonary capillaries. This is only partially offset by a protein osmotic pressure gradient due to the restricted movement of larger plasma proteins (Ware and Matthay 2005).

Cardiogenic or volume overload edema is characterized by a rapid increase in hydrostatic pressure. This leads to an increase in fluid filtration from the microcirculation. An increase in pulmonary venous pressure from an increase in left ventricular end-diastolic pressure and left atrial pressure usually causes the increased hydrostatic pressure. With elevations of 18 to $25 \mathrm{~mm} \mathrm{Hg}$, edema will begin in the perimicrovascular and peribronchovascuar interstitial spaces. Beyond $25 \mathrm{~mm} \mathrm{Hg}$, fluid that has a low protein concentration will begin to be seen in the alveolar spaces (Staub 1974; Ware and Matthay 2005).

Noncardiac pulmonary edema is characterized by an increase of fluid with a high plasma protein concentration into the interstitium and alveoli due to an increase in vascular permeability. The amount of fluid that accumulates in the alveolar space depends upon the degree of interstitial edema, whether or not the alveolar epithelium has been injured, and the ability of the alveolar epithelium to actively transport the alveolar 
fluid. There is usually a decreased capacity to resolve the alveolar edema fluid when the alveolar epithelial damage is due acute lung injury (Matthay, Folkesson et al. 2002; Ware and Matthay 2005).

Acute Lung Injury (ALI)

First described in 1967, acute lung injury (ALI) and acute respiratory distress syndrome (ARDS) are characterized by "the abrupt onset of clinically significant hypoxemia with presence of diffuse pulmonary infiltrates" (Wheeler and Bernard 2007). Due to an increase in vascular permeability, the infiltrates appear on radiographs as pulmonary edema. The number of cases that occur every year are in the hundreds of thousands (Goss, Brower et al. 2003). Within 7-10 days, about half of the patients with ALI will have died. Within the $50 \%$ that survive, a majority of them will have a prolonged recovery. Up $10 \%$ of those with ALI will be on ventilation for more than a month. The lung function of ALI survivors will not return for more than 6-12 months (Ashbaugh, Bigelow et al. 1967; Wheeler and Bernard 2007).

The disorder can be caused by indirect or direct injury. Examples of direct injury include: alveolar hemorrhage, drowning, fat and amniotic-fluid embolism, gastric aspiration, pneumonia, pulmonary contusion, reperfusion (pleural effusion drainage, embolectomy), smoke and toxic gas inhalation, and unilateral lung re-implantation. Examples of indirect injury include: pancreatitis, severe sepsis, shock, salicylate or narcotic overdose, blood transfusion (Wheeler and Bernard 2007).

ALI manifests as ARDS when the acute lung injury is severe. ARDS has a mortality rate of $30-50 \%$. ARDS is characterized by the infusion of the alveolar air 
spaces with fluid containing a high plasma protein concentration typical of

noncardiogenic pulmonary edema. ARDS can develop in response to inflammatory stress from both indirect and direct causes of acute lung injury including sepsis, trauma, and severe pneumonia (Matthay, Folkesson et al. 2002; Ware and Matthay 2005; Guidot, Folkesson et al. 2006).

Early acute lung injury is characterized by an initiation and perpetuation of inflammation by various cytokines such as tumor necrosis factor, interleukin 1, and interleukin 8. As a result of increased oxidant stress and protease activity, widespread lung collapse (atelectasis) occurs due to decreased surfactant production and inactivation of residual surfactant. Also, elastases present in the lung cause structural damage to the lung leading to injury of both the epithelial cells and the alveolar-capillary network. Alveolar fluid accumulation is thereby increased due to the damage incurred by the epithelial cell barrier. The epithelial cell layer damage also delays patient recovery by slowing resolution of the pulmonary edema (Sartori and Matthay 2002; Wheeler and Bernard 2007).

Pulmonary Edema, Acute Lung Injury, and Alveolar Fluid Clearance

Pulmonary edema is a condition that is life threatening. Pulmonary edema develops either due to an increase in permeability of the lung alveolar-epithelial barrier or from an increase in lung vascular hydrostatic pressure. Often it will develop into acute respiratory failure, which is commonly caused by ALI and ARDS. Much has been learned about the pathophysiology of ALI/ARDS. They are well defined pathologies and readily recognized clinical disorders. They can be caused by clinical insults to the lung 
or by predispositions to lung injury. Increased pulmonary edema, alveolar flooding, and respiratory failure are characterized by alveolar epithelial and lung endothelial injury in the early stages of ALI/ARDS. In order for ALI/ARDS to be resolved, it is necessary that the alveolar space have its pulmonary edema fluid reabsorbed (airway fluid clearance). Resolution of experimentally induced pulmonary edema and acute lung injury requires intact alveolar epithelial fluid transport (Ware and Matthay 2001; Wheeler and Bernard 2007).

Active transport of salt and water from the lung across the epithelial barrier is required for airway fluid clearance to take place. Airway fluid clearance requires apical ion transporters for sodium (epithelial sodium channels) and chloride (cystic fibrosis transmembrane conductance regulator - CFTR). Also, the $\mathrm{Na}^{+} / \mathrm{K}^{+}$-ATPase in epithelial cells plays a centrally important role in airway fluid clearance. If the alveolar epithelium is injured and the barrier disrupted, ion channels can be down-regulated which will further reduce net airway fluid clearance. This process results in enhanced alveolar edema. The rate of airway fluid clearance is controlled by catecholamine-dependent, as well as catecholamine-independent mechanisms (Matthay, Folkesson et al. 2002; Guidot, Folkesson et al. 2006). Understanding the processes that upregulate epithelial sodium and chloride transport, enhancing airway fluid clearance, can potentially lead to more effective treatments for some types of airway lung injury and pulmonary edema (Sartori and Matthay 2002; Mutlu, Koch et al. 2004; Mutlu and Sznajder 2005). (Figure 1-3). 


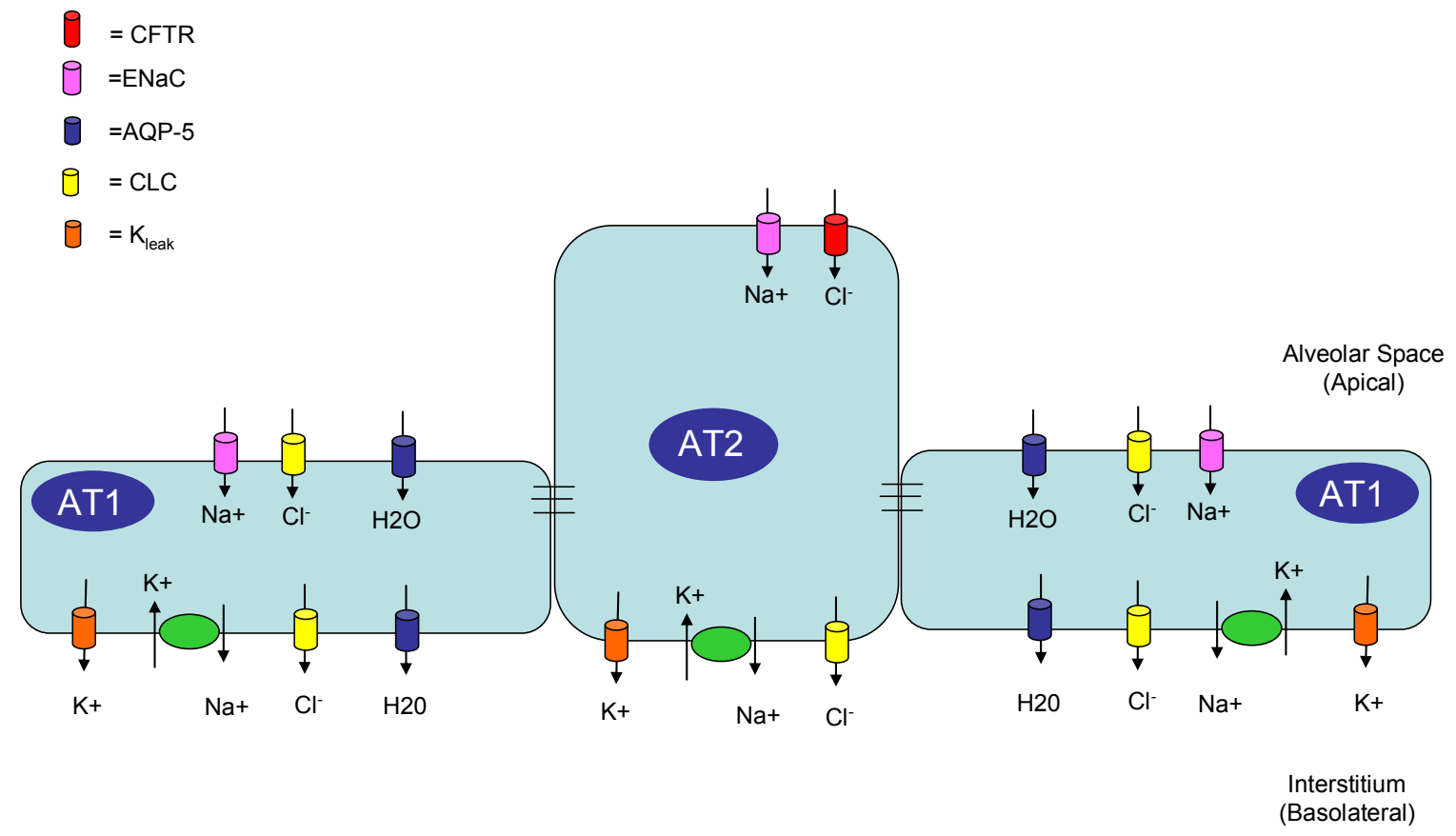

Figure 1-3. Airway Fluid Clearance 


\section{CFTR, the Epithelial Sodium Channel (ENaC), and the Beta -2 Adrenergic \\ Receptor $\left(\boldsymbol{\beta}_{2}-\mathrm{AR}\right)$ in Alveolar Fluid Clearance}

While most agree that active sodium transport has a primary role in

transepithelial movement of salt and water in alveolar epithelial of lung, an important role for CFTR mediated upregulation of airway fluid clearance is being established (Matthay, Robriquet et al. 2005). The basic model for vectorial ion transport (sodium and chloride) is that salt movement creates a slight osmotic gradient in the interstitial space outside the alveoli that removes water from the distal air spaces of the lung (airway fluid clearance). CFTR and epithelial sodium channels $(\mathrm{ENaC})$ are expressed in distal and alveolar airway epithelia (Engelhardt, Zepeda et al. 1994). A study in alveolar type II cells suggests that cAMP driven sodium uptake may depend initially on the uptake of chloride (Jiang, Ingbar et al. 1998). It has been shown that alveolar type II cells express CFTR protein and CFTR can be detected via patch-clamp analysis, short-circuit studies, as well as in vitro vectorial fluid transport assays. In vivo evidence also indicates that, in the intact lung, CFTR plays an important role in cyclic adenosine monophosphate (cAMP) activated airway fluid clearance (Matthay, Robriquet et al. 2005; Guidot, Folkesson et al. 2006).

Beta $(\beta)$-Adrenergic receptors $\left(\beta_{2}-\mathrm{AR}\right)$ are present in the alveolar epithelium where they upregulate the active $\mathrm{Na}^{+}$transport and thereby accelerate airway fluid clearance form the alveolar airspace (Mutlu, Adir et al. 2005). $\mathrm{B}_{2}$-AR signaling increases transepithelial $\mathrm{Cl}^{-}$movement across airway and alveolar epithelial cells through CFTR (Engelhardt, Zepeda et al. 1994; Jiang, Ingbar et al. 1998). Not only does activation ofB $\mathrm{B}_{2}$-AR upregulate CFTR-dependent chloride transport, but it also upregulates $\mathrm{ENaC}$ - 
dependent sodium transport (Guidot, Folkesson et al. 2006). A study of alveolar type II cells kept at an apical air-liquid interface shows that $\beta$-adrenergic agonists cause activation of apical chloride channels and enhanced sodium absorption (Jiang, Ingbar et al. 2001) (Figure 1-4).

Further studies in the mouse and human came to the same conclusion. Using a pharmacological approach, namely glibenclamide, it was suggested that cAMPstimulated airway fluid clearance from the distal airspaces of the lung may require chloride uptake and CFTR-like transport (Factor, Mutlu et al. 2007). It is true that the inhibitory effect of glibenclamide inhibitory is not specific for CFTR, as it can also inhibit potassium channels. However, these results are confirmed when CFTRinh-172 (a specific CFTR inhibitor) is used (Fang, Song et al. 2006).

More direct evidence has also been provided from in vivo studies using the $\triangle$ F508-CFTR -CFTR mouse model. While there is evidence for enhanced sodium absorption in the upper airways due to the absence of CFTR (Stutts, Canessa et al. 1995), it is becoming clear that, in the distal air spaces, an absence of CFTR decreases the stimulated salt and fluid transport (Matthay, Robriquet et al. 2005). This is similar to the effect of CFTR on sodium absorption in the human sweat duct (Reddy, Light et al. 1999). In $\triangle$ F508-CFTR mice, fluid clearance does not increase in the presence of either $\beta$ adrenergic agonists or forskolin to the same extent as do wtCFTR mice (Mutlu, Koch et al. 2004). These studies show that CFTR is essential for cAMP -mediated enhancement of airway fluid clearance from the distal airspaces of the lung (Fang, Fukuda et al. 2002). In addition, transfer of the $\beta_{2}$-AR gene was studied in the alveolar epithelium of the $\triangle$ F508-CFTR mice. Again, it was found that, compared to wild-type controls, the 


$$
\begin{aligned}
& 0=\text { CFTR } \\
& \text { O }=\text { ENaC } \\
& 0=\text { AQP }-5 \\
& \theta=\text { CLC } \\
& \theta=K_{\text {leak }}
\end{aligned}
$$

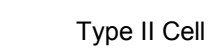

Active Transport Produces to Mini-osmotic Gradient in Interstitium
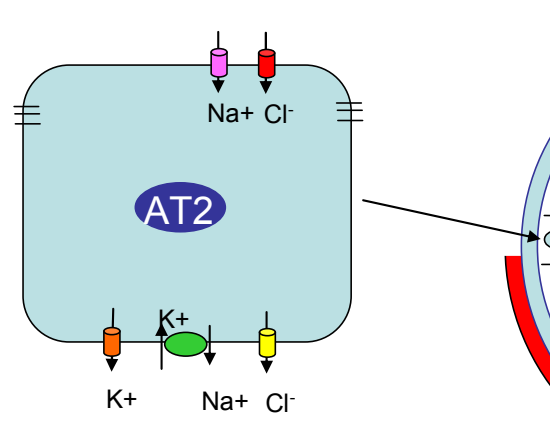

$10 \mathrm{uM}$

$10 \%$ of Surface Area
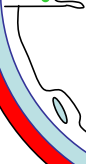

(1)

Distal

Airway

$\backslash$ Lymph Drainage

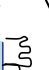

$\frac{2}{2}$
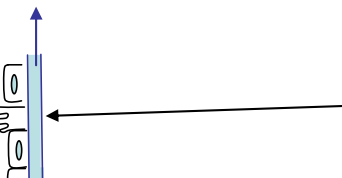

$\frac{0}{0}$

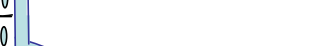

(s)

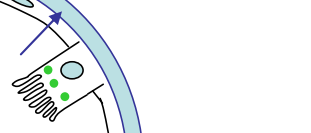

Alveolus
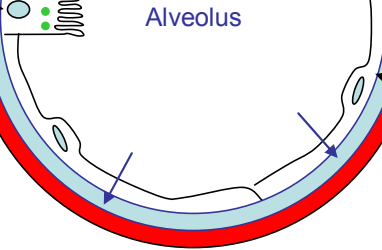

2
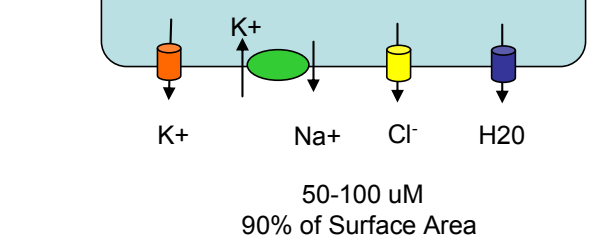

Figure 1-4. Role of CFTR in Airway Fluid Clearance 
absence of functional CFTR hinders active alveolar $\mathrm{Na}+$ transport. This suggests that much of the $\beta$-Adrenergic upregulation of $\mathrm{Na}+$ flux is regulated by CFTR (Mutlu, Adir et al. 2005). Furthermore, it is important to note that while $\Delta$ F508CFTR -CFTR mice have normal basal airway fluid clearance rates, they are unable to increase active sodium transport in response to edema formation (Fang, Fukuda et al. 2002; Mutlu, Adir et al. 2005).

Thus, it seems that there is a close working relationship between CFTR, ENaC, and the $\beta_{2}$-AR in regulating airway fluid clearance. Both the $\beta_{2}-\mathrm{AR}$ and CFTR seem to be required to upregulate active alveolar $\mathrm{Na}^{+}$transport. It is of concern for patients with cystic fibrosis that they may be impaired in their ability to effectively initiate airway fluid clearance in response to airway lung injury and pulmonary edema (Mutlu, Adir et al. 2005).

\section{CFTR Interacting Partners}

\section{Protein-Protein Interaction in the Lung}

It is common for macromolecular complexes of cells to form on membrane domains to increase signaling efficiency (Li and Naren 2005). CFTR-dependent chloride transport is stimulated by isoproterenol (Haws, Finkbeiner et al. 1994). In airway epithelial cells, the major adrenergic receptor isoform expressed is the $\beta_{2}$-AR (Abraham, Kottke et al. 2003). It has recently been established that both CFTR and the $\beta_{2} \mathrm{AR}$ can, through their PDZ motif, bind NHERF1/ ERM binding phosphoprotein of $50 \mathrm{kDa}$ (EBP50) (Naren, Cobb et al. 2003). Also, G proteins are likely to be in the complex. 
These proteins can associate with the $\beta_{2} \mathrm{AR}$ and protein kinase A (PKA) that anchors to A-kinase-anchoring proteins (AKAP) (ezrin). When activated by isoproterenol, the $\beta_{2}$ AR stimulates the $G_{s}$ pathway leading to an increase in cAMP. The local increase in cAMP then allows PKA to become active, phosphorylating and activating CFTR. When the PDZ motif is deleted from CFTR, the interaction is both physically and functionally uncoupled. This effect is specific for $\beta_{2} \mathrm{AR}$ and is not seen with other receptors such as the adenosine receptor pathway (Naren, Cobb et al. 2003).

\section{Amino-Terminal SNARES}

Syntaxin 1A and soluble NSF attachment protein of 23 kilodaltons $(\mathrm{kDa})$ (SNAP-23) are known as target soluble NSF attachment protein receptors (t-SNARES). It has been shown that they are both localized to the apical membrane of epithelial cells. It has also been shown that the function of CFTR can be down-regulated by Syntaxin 1A and SNAP-23 (Naren, Nelson et al. 1997; Naren, Quick et al. 1998; Peters, Qi et al. 1999; Cormet-Boyaka, Di et al. 2002). Syntaxin 1A interacts with the amino-terminal (Nterminal) domain of CFTR (Naren, Quick et al. 1998). This interaction is also physiologically significant. CFTRs activity can be increased by $2-4$ fold by perturbing the protein-protein with Syntaxin 1A. Likewise, it has been demonstrated that when SNAP-23 binds to the N-terminus of CFTR, functional CFTR activity decreases. These two proteins (Syntaxin 1A and SNAP-23) work synergistically to inhibit CFTR function, resulting in greater inhibition together compared to either protein alone. (Naren, Nelson et al. 1997; Cormet-Boyaka, Di et al. 2002). 


\section{Carboxy-Terminal PDZ Motifs}

Among the various conserved protein domains found in mammalian proteins, PSD95/ DlgA /zo-1 (PDZ) domains are among the most common (Shenolikar, Voltz et al. 2004). PDZ domains are made up of 80-100 amino-acid sequences. Protein-protein interactions are mediated through these domains by binding to short peptide sequences that are usually found in the carboxyl (C) termini of protein binding partners. PDZ domains play a role in a variety of cellular functions including: mediating proteinprotein interactions, assisting in the polarized localization of various proteins, cellular colocalization (transporters, signaling proteins, and channels) regulating endocytic trafficking and controlling channel function and transporter function (Brone and Eggermont 2005). PDZ domains are found in several ABC transporters. CFTR, ABCA1, ABCA7, MRP2 and MRP4 have C terminal PDZ-binding motifs (Hegedus, Sessler et al. 2003). The CFTR PDZ motif sequence is aspartic acid- threonine-arginineleucine (DTRL). This motif allows CFTR to bind several PDZ domain containing proteins such as $\mathrm{Na}+/ \mathrm{H}+$ exchanger regulatory factor isoform-1 (NHERF1), NHERF2, NHERF3, or CFTR-associated protein - $70 \mathrm{kDa}$ (CAP70 or NHERF4) and CFTRassociated ligand (CAL) (Wang, Raab et al. 1998; Guggino 2004; Li and Naren 2005; Thelin, Hodson et al. 2005). C-terminal ezrin, radixin, or moesin (ERM)-binding domain is present in NHERF1 and NHERF2, allowing them to interact with ezrin, radixin, or moesin. This allows proteins that bind NHERF to interact with the actin cytoskeleton in the apical membrane of polarized epithelial cells (Short, Trotter et al. 1998; Sun, Hug et al. 2000). 
Nucleotide Binding Domains (NBDs) - Scaffolding Proteins

It has been proposed that the nucleotide binding domain itself may allow CFTR to function as an actin-binding protein. It has been demonstrated that CFTR function can be regulated by the actin cytoskeleton (Prat, Xiao et al. 1995; Cantiello 1996; Prat, Cunningham et al. 1999). Also, using a lipid bilayer system and atomic force microscopy (AFM), purified human CFTR has been shown to interact directly with CFTR (Chasan, Geisse et al. 2002). And CFTR has been shown to exist as a dimer (Li, Roy et al. 2004). Also, it has been shown that dimerization of CFTRs nucleotide-binding domains are involved in the regulation of ion channel activity (Vergani, Lockless et al. 2005). Interestingly, a comparison of the amino acid sequences between CFTR and various actin binding proteins shows strong homology. It turns out that the two nucleotide binding domains of CFTR have sequence homology with actin capping and cross-linking proteins such as filimin and alpha $(\alpha)$ - actinin. Also, consensus sequences of strong homology exist between the nucleotide binding domains (NBDs) and the actin binding proteins gelsolin, severin, and villin (Prat, Xiao et al. 1995). If the NBDs are indeed interacting directly with the actin cytoskeleton, this may in part explain the ability of the actin cytoskeleton to regulate CFTR channel activity.

\section{Hsp90 and Chloride Channel Regulation}

Hsp90 is a chaperone protein that binds to other proteins that are at a late stage of folding and consequently in a near native conformation (Jakob, Lilie et al. 1995; Young, Moarefi et al. 2001). HSP90 is an ATP dependent chaperone (Prodromou, Roe et al. 1997). ATP binds Hsp90 in the highly conserved $25 \mathrm{kDa}$-terminal domain. This is the 
site of action for the Hsp90 inhibitor, Radicicol. Radicicol is a natural compound that inhibits Hsp90 with nanomolar affinity by occupying the nucleotide binding pocket within the N-terminal domain (Roe, Prodromou et al. 1999).

Hsp90 has a demonstrated role in regulation of $\mathrm{Cl}^{-}$channel function. CLC-2, is a chloride channel that has been shown to play a role in various physiological functions including epithelial fluid transport (Jentsch, Poet et al. 2005). In HEK-293 cells stably expressing CLC-2, an association with Hsp90 has been demonstrated via immunoprecipitation and mass spectroscopy. Also, Radicicol was shown to reduce plasma membrane channel abundance without affecting total amounts of CLC-2. Functional experiments using whole cell patch clamping show that inhibition of Hsp90 reduced CLC-2 activity and association of Hsp90 with CLC-2 leads to an increase in channel activity (Hinzpeter, Lipecka et al. 2006). Interestingly, while it has been shown that Hsp90 may be found in association with CFTR (Loo, Jensen et al. 1998), the functional importance of this protein-protein has not been thoroughly investigated.

\section{Hypothesis and Specific Aims}

The hypothesis of this project is that a functionally relevant association exists between CFTR and Hsp90. In testing this hypothesis, (a) the association of CFTR and Hsp90 is confirmed via crosslinking and immunoprecipitation of CFTR from stably transfected HEK-293 cells, electrophoretic separation of cross-linked proteins, and protein identification via SDS-PAGE, western blotting, and mass spectroscopy. Also, this hypothesis is tested by (b) functionally assessing the affect of Hsp90 on CFTR 
function via using chamber analysis, two-electrode voltage clamp analysis, preliminary in vivo animal studies, and protein phosphorylation. 


\section{CHAPTER 2: PURIFICATION OF FLAG-CFTR FROM HEK-293 CELLS}

\section{Materials and Methods}

Generation of HEK-Flag-CFTR Cell Line

HEK-Flag-CFTR cell line was generated in collaboration with the John Kappes laboratory of The University of Alabama at Birmingham as described previously (Naldini, Blomer et al. 1996; Wu, Wakefield et al. 2000). HEK-293 cells were plated on 100-mm-diameter dishes at a density of approximately $10^{6}$ cells per dish. The following day, cells were transfected using the three-plasmid lentiviral vector system. To produce the virus, $25.0 \mu \mathrm{g}$ of vector genome plasmid containing Flag-CFTR, $50.0 \mu \mathrm{g}$ of a backbone plasmid expressing HIV-1 gag and pol genes, and $5.0 \mu \mathrm{g}$ of a plasmid that expresses vesicular stomatitis virus (VSV) G protein were used to transfect each 100-mm dish of cells. The transfection was performed using a Profection kit (calcium chloride) from Promega. On the following day, the medium was replaced, and 2 days after transfection, supernatant from vector-producing 293T cells was harvested, passed through a $0.45-\mu \mathrm{m}$-pore-size filter to remove producer cells, and then subjected to centrifugation at $4^{\circ} \mathrm{C}$ and $27,500 \times g$ for 30 min to concentrate the virus. The virus pellet was resuspended in $1.0 \mathrm{ml}$ of DMEM. Concentrated vector $(0.8 \mathrm{ml})$ was used to infect 1 x $10^{6}$ HEK-293 cells in a 100-mm dish. After 2 days, infected cells were split into two 100-mm dishes following a 5 minute trypsin treatment. The infected cells were selected in Dulbecco's modified Eagle's medium (DMEM) containing puromycin [5 $\mu \mathrm{g} / \mathrm{mL}]$. After 12 days of puromycin selection, a microscope was used to identify individual 
colonies. The HEK-Flag-CFTR cells were cultured and maintained at $37^{\circ} \mathrm{C}$ in DMEM containing 10\% Serum Supreme (Lonza Group Ltd, Switzerland), $100 \mathrm{U}$ of penicillin, and $0.1 \mathrm{mg} / \mathrm{ml}$ of streptomycin (Sigma).

\section{Protein Purification}

HEK-Flag-CFTR cells were lysed PBS $0.2 \%$ Triton X-100 with protease inhibitors (aprotenin $[1 \mu \mathrm{g} / \mathrm{mL}]$, leupeptin $1 \mu \mathrm{g} / \mathrm{mL}$, pepstatin $1 \mu \mathrm{g} / \mathrm{mL}$, PMSF [400 $\mu \mathrm{M}]$ ). The lysate is centrifuged at $16,000 \mathrm{x}$ g for $10 \mathrm{~min}$ at $4^{\circ} \mathrm{C}$. Then, immunoprecipitation is performed on the lysate overnight at $4 \mathrm{oC}$ while rotating using Flag antibody conjugated beads (Seize Immunoprecipitation Kit, Pierce Chem. Co.). The proteins are then bound to spin columns, spun for [insert] minutes at 3,000 $\mathrm{g}$ and washed with lysis buffer. Proteins were eluted from beads using 100mM Glycine $\mathrm{pH} 2.2(0.2 \%$ Triton) into $1.5 \mathrm{M}$ Tris ( $\mathrm{pH} 8.8)$. The eluted protein was then was separated on a 4-15\% SDS polyacrylamide gel (SDS-PAGE) and visualized with Gel Code Blue (Pierce.)

\section{Purification of the Cross-Linked Macromolecular Complex}

HEK-Flag-CFTR cells cross-linked with dithiobis(succinimidyl)propionate (DSP) were solubilized in 1X RIPA buffer ( $\mathrm{NaCl} 140 \mathrm{mM}$, Nonidet P40 (NP40) 1\%, Nadeoxycholate $0.5 \%$, sodium dodecyl sulfate (SDS) $0.1 \%$, Tris-HCl $50 \mathrm{mM}, \mathrm{pH} 8.0$ ) plus protease inhibitors on ice for $20 \mathrm{~min}$, and lysates were spun at $15,000 \mathrm{~g}$ for $15 \mathrm{~min}$ at $4^{\circ} \mathrm{C}$ to pellet insoluble material. $40 \mu \mathrm{g}$ of the clarified protein lysate (protein was estimated using Bio-Rad Protein Assay \#500-0006). Anti-Flag beads were incubated with the cross-linked supernatant overnight at $4^{\circ} \mathrm{C}$ with constant mixing on a rotator. After 
washing the beads three times with RIPA buffer, the cross-linked proteins were eluted with sample buffer. During this process, $2.5 \%$ B-mercaptoethanol ( $\beta \mathrm{ME})$ cleaved the disulfide bond of the DSP, separating the proteins. The immunoprecipitated proteins were separated on $4-15 \%$ gel. For western blotting, proteins were transferred to a polyvinylidene difluoride (PVDF) membrane, blocked with TBST containing 5\% milk, and blotted using $\alpha$-CFTR monoclonal antibody (R1104) and $\alpha$-HSP-90 monoclonal antibody (HSP90/F8).

\section{CFTR Physiological Assay - Iodide Efflux}

CFTR-mediated halide conductance was measured using the iodide efflux assay (Chang et al., 1993). Calu-3 and HEK-293 cells were grown to confluency on $60 \mathrm{~mm}-$ dishes. The cells were loaded with 136 millimolar (mM) sodium iodide (NaI) for 1 hour at $37{ }^{\circ} \mathrm{C}$. The dishes were washed 5 times with $1 \mathrm{~mL}$ of warm $136 \mathrm{mM}$ sodium nitrate $\left(\mathrm{NaNO}_{3}\right)$ at $37{ }^{\circ} \mathrm{C}$ to remove extracellular NaI from the cells. The functional activity of CFTR is assessed by stimulating the cells with agonist and measuring the release of $\mathrm{NaI}$ (through CFTR channels) into the extracellular buffer (NaNO3). For 10 minutes, the cells were incubated with $1 \mathrm{~mL}$ of warm $136 \mathrm{mM} \mathrm{NaNO}_{3}$. The buffer was collected and replaced every minute. The first four minutes of incubation were considered as the baseline period. The fifth through tenth samples contained CFTR agonists. The reagents being investigated for their effect on CFTR function were either pre-incubated prior to the assays initiation, were added to both the baseline and activation phases of the assay, or were added to the activation phase alone. The iodide concentration in each $1 \mathrm{~mL}$ aliquot was assessed using a ThermoOrion 720 iodide sensitive electrode (Orion Research, Inc., Boston, MA). The iodide was converted to nanomoles/min and expressed 
as mean values (+/-) standard deviation (SD) using the Student's $t$ test. A value of probability $(\mathrm{P})<0.05$ was used as a cut-off for determination of statistical significance.

\section{Mass Spectrometry}

Identification of FLAG-CFTR was confirmed using liquid chromatography coupled to electrospray-ionization quadrupole ion trap mass spectrometry (LC-ESI-QITMS) (Gadgil, Pabst et al. 2003). Samples were analyzed on a ThermoFinnigan LCQ DECA mass spectrometer. Picofrit columns (360 am outer diameter (OD), 75 am inner diameter (ID), $15 \mu \mathrm{m}$ orifice, New Objective, Woburn, MA, USA) were packed with 9-10 cm of C18 silica based reverse-phase packing material (5 um particle diameter, $200 \AA$ pore size, MAGIC C18) from Michrom BioResources Auburn, CA, USA. Samples were extracted using ZipTip C18 microcolumns, eluted with 50\% acetonitrile, dried, and redissolved in $4 \mu \mathrm{L}$ of $0.1 \%$ Trifluoroacetic acid (TFA) in water. This purified sample was injected into a Surveyor LC system (Thermo Finnigan, San Jose, CA, USA). Chromatography of FLAG-CFTR was performed by the Picofrit column using a linear gradient of increasing acetonitrile $[100 \%$ solution $\mathrm{A}$ (water with $0.1 \%$ formic acid) to $50 \%$ solution B ( $90 \%$ acetonitrile, $10 \%$ water, $0.1 \%$ formic acid], at a flow rate of 400 nanoliter (nL) / minute, which was then sprayed into the mass spectrometer. Three types of spectra were acquired: a full-scan of the mass spectrum, a zoom scan of the two most prominent ions, and MS/MS scans of the two most prominent ions. The spectra were analyzed by SEQUEST software (ThermoFinnigan) which uses an algorithm to match observed peptide masses and MSMS product ion masses to the theoretical values for all proteins in the database. FLAG-CFTR identity was also determined using a different 
form of mass spectrometry called MALDI-TOF (matrix assisted laser desorption ionization - time-of-flight). Spectra were scored using a MOWSE scoring algorithm (Pappin, Hojrup et al. 1993).

\section{Results}

\section{Purification of CFTR (Microgram Quantities)}

Here, we describe the characterization of a novel CFTR expressing cell line, the FLAG-CFTR HEK-293 cells. These cells were developed to provide a cell line that would allow a both a functional and biochemical characterization of wild-type CFTR. In collaboration with Dr. John Kappes (University of Alabama at Birmingham), we developed a human embryonic kidney (HEK-293) cell line expressing wild-type CFTR. Using this cell line has several advantages. First, it is of human origin, unlike the LLCPK1 (pig), C127 (mouse), or BHK (hamster). Second, compared to LLCPK1 and MDCK cells, FLAG-CFTR HEK-293 cells are easier to transfect. Third, the CFTR in these cells respond to various agonists, such as adenosine and $\beta$-adrenergic receptor agonists. This is important because not all cells lines respond to this agonist profile (i.e., BHK cells). And fourth, the CFTR in these cells are engineered with a FLAG-tag on the fourth extracellular loop (Figure 2-1). This allows for a high degree of protein purification in quantities sufficient for mass spectroscopy. It also offers the ability to immunoprecipitate larger quantities of proteins that interact with CFTR. The cells were lysed in RIPA buffer and $40 \mu \mathrm{g}$ of the clarified protein was analyzed by Western Blot using an $\alpha$-CFTR monoclonal antibody (R1104). As expected a $170 \mathrm{kDa}$ band of FlagCFTR was detected (Figure 2-2). 


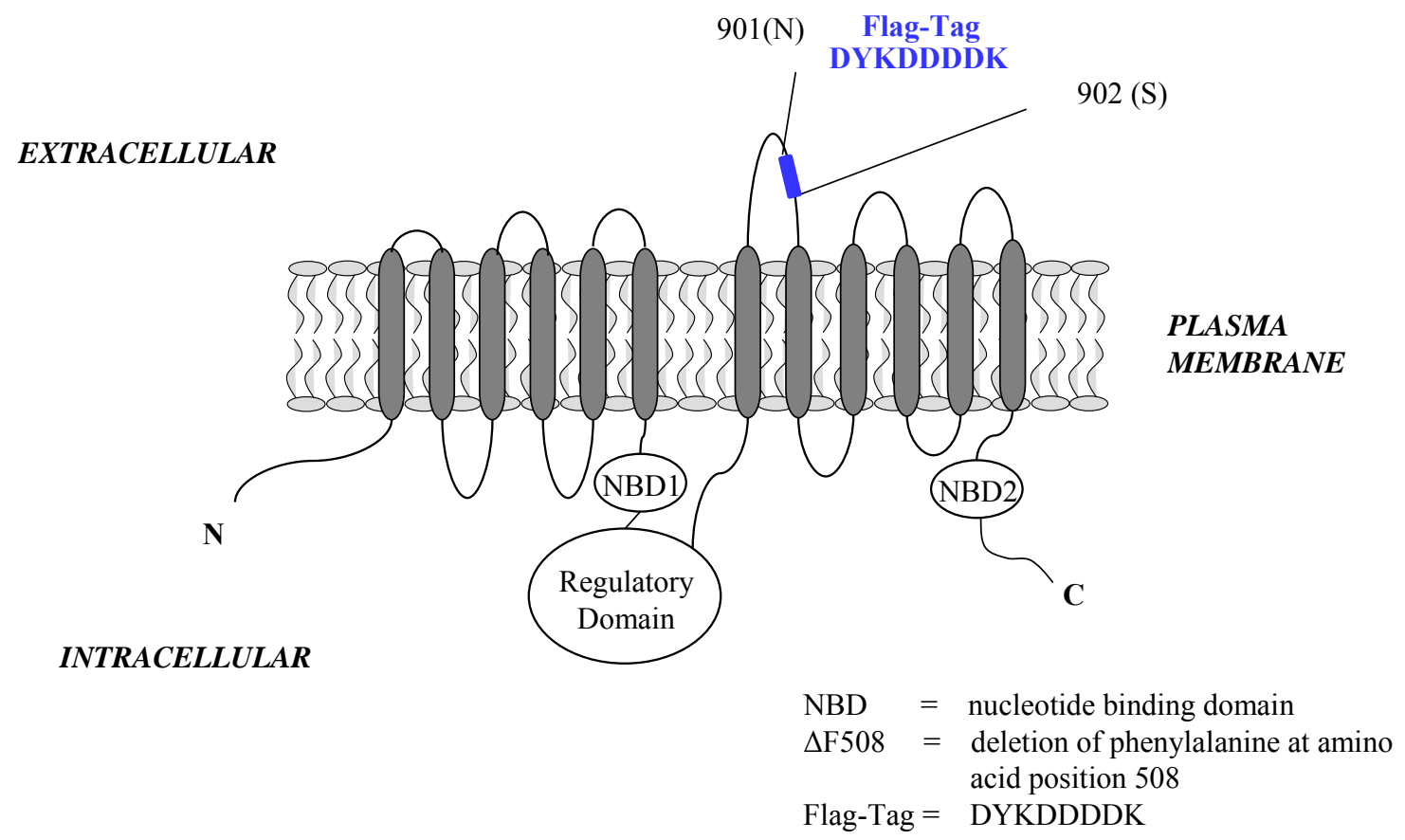

Figure 2-1. Flag-CFTR 
$40 \mathrm{mg}$ protein

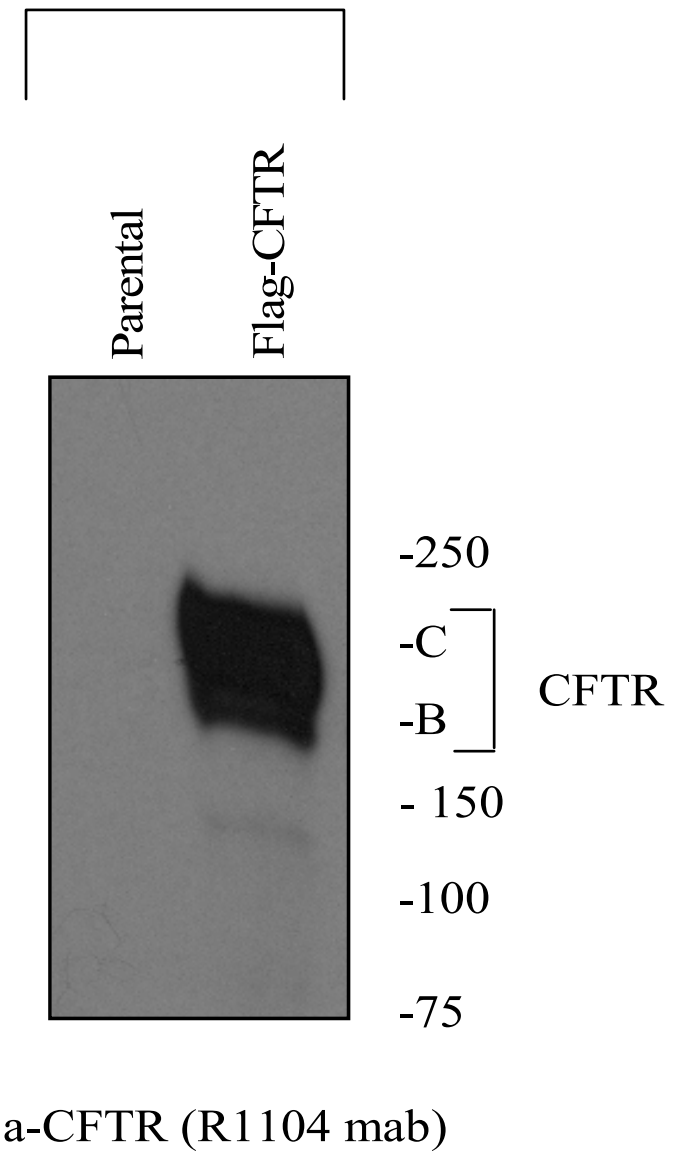

Figure 2-2. HEK-Flag-CFTR Cells Express Detectable CFTR 
HEK-293-FLAG-CFTR cell lysates were compared to BHK cells transfected with wild-type (WT)-CFTR and CFTRHis10. Each lane was loaded with $40 \mu \mathrm{g}$ of protein and probed with CFTR mAb (R1104). With a 10 second exposure, the HEK-293-CFTR transfected cells compared to clearly shows a much greater amount of protein being expressed (Figure 2-3).

Next, the amount of FLAG-CFTR expressed in these cells in these cells was quantified using MBP-C-CFTR as a standard. A confluent $60-\mathrm{mm}$ dish $\left(\sim 10^{6}\right.$ cells $)$ yielded $1320 \mu \mathrm{g}$ of protein (3.3 millligrams $(\mathrm{mg}) /$ milliliter $(\mathrm{mL})$ ). $20 \mu \mathrm{g}$ of protein was loaded on a gel along with MBP-CFTR (0.5 ng-10.0 nanograms (ng)). As determined from the standard curve, 0.851 pmoles ( $125 \mathrm{ng}$ ) of CFTR is expressed in $20 \mu \mathrm{g}$ of protein lysate. This corresponds to $8.2 \mu \mathrm{g}$ of total FLAG-CFTR per $10^{6}$ cells (Figure 2-4).

\section{Flag-CFTR Cell Line Functional Assay}

Cells containing CFTR respond to agonists that increase the PKA phosphorylation of CFTR (forskolin, 3-Isobutyl-1-methylxanthine (IBMX), and cpt.cAMP) (Anderson, Rich et al. 1991; Cheng, Rich et al. 1991). It is expected that if the Flag-CFTR is functional in the stably transfected HEK-293 cells, it will respond to agonists known to activate CFTR. Using the iodide efflux assay, the HEK-Flag-CFTR cells were shown to have functional CFTR activity. As anticipated, the HEK-FLAGCFTR cells responded to forskolin, 3-Isobutyl-1-methylxanthine (IBMX), and cpt.cAMP $(10 \mu \mathrm{M}, 50 \mu \mathrm{M}$, and $100 \mu \mathrm{M}$ respectively), isoproterenol $(100 \mu \mathrm{M})$, and adenosine (100 $\mu \mathrm{M})$. This demonstrates that the Flag-CFTR expressed within the cells is able to exhibit functional activity (Figure 2-5). 


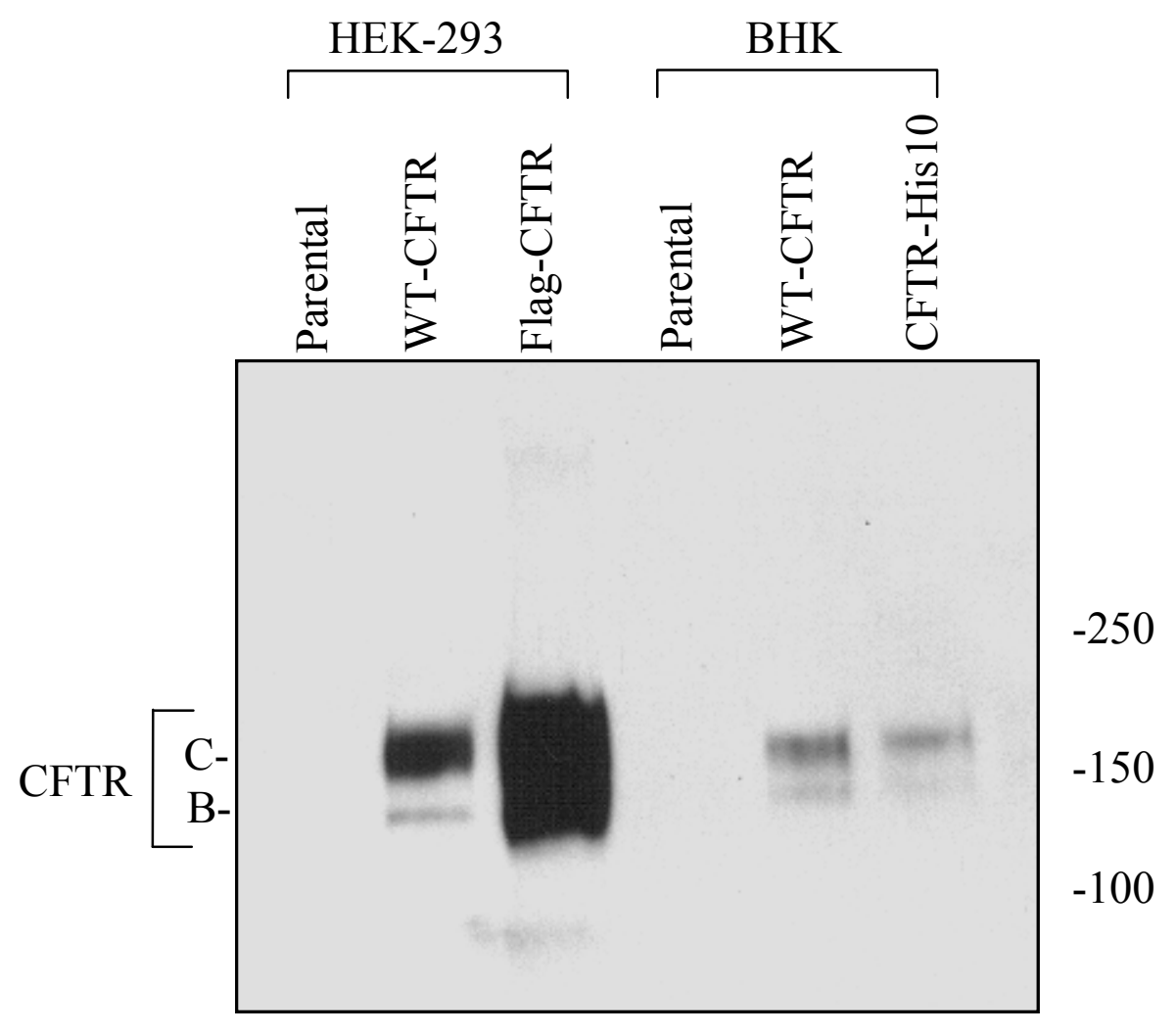

Figure 2-3. HEK-Flag-CFTR and BHK Cell Expression of CFTR 


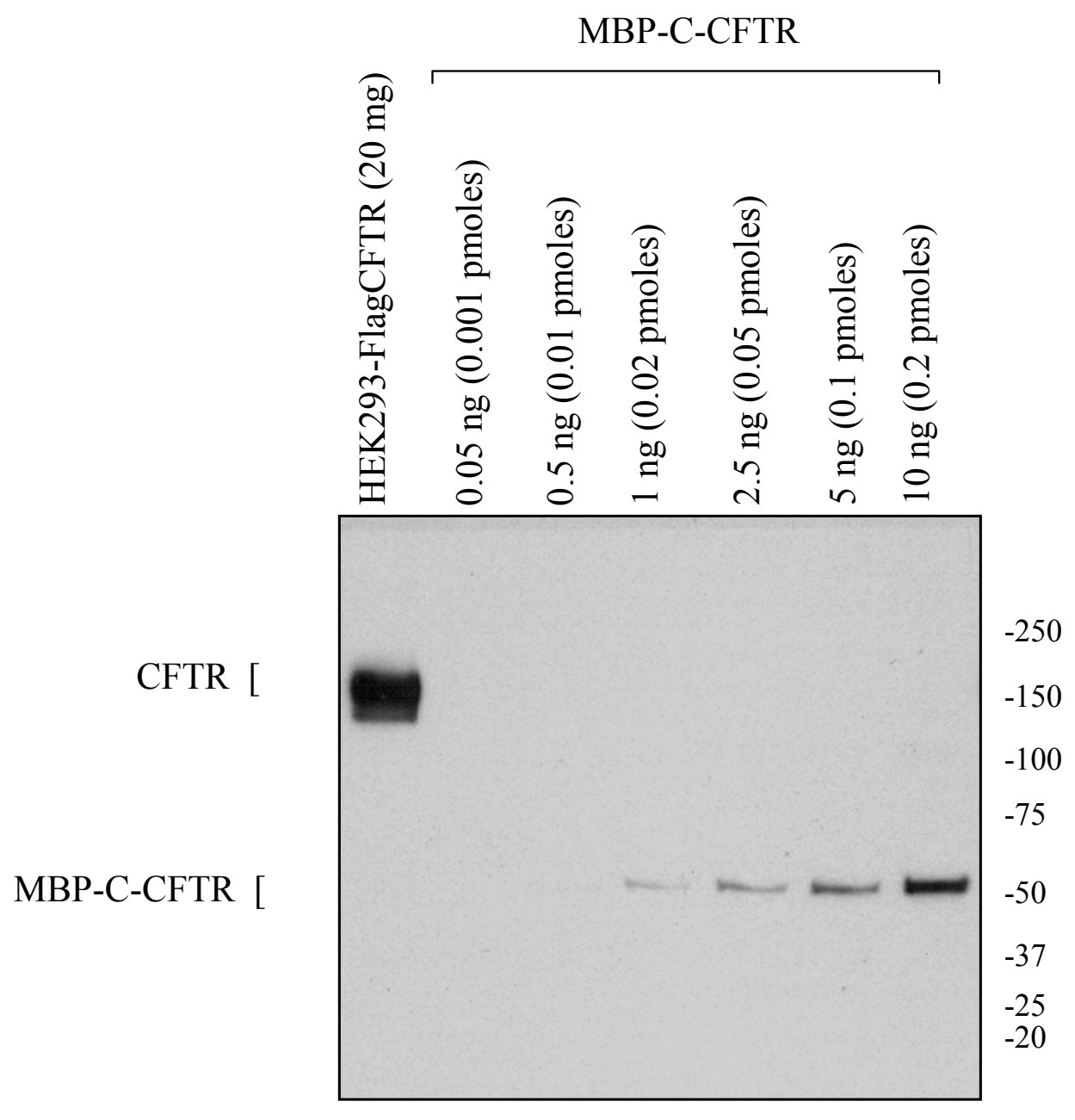

Figure 2-4. Quantitation of HEK-Flag-CFTR 


\section{FLAG-CFTR lodide Efflux}

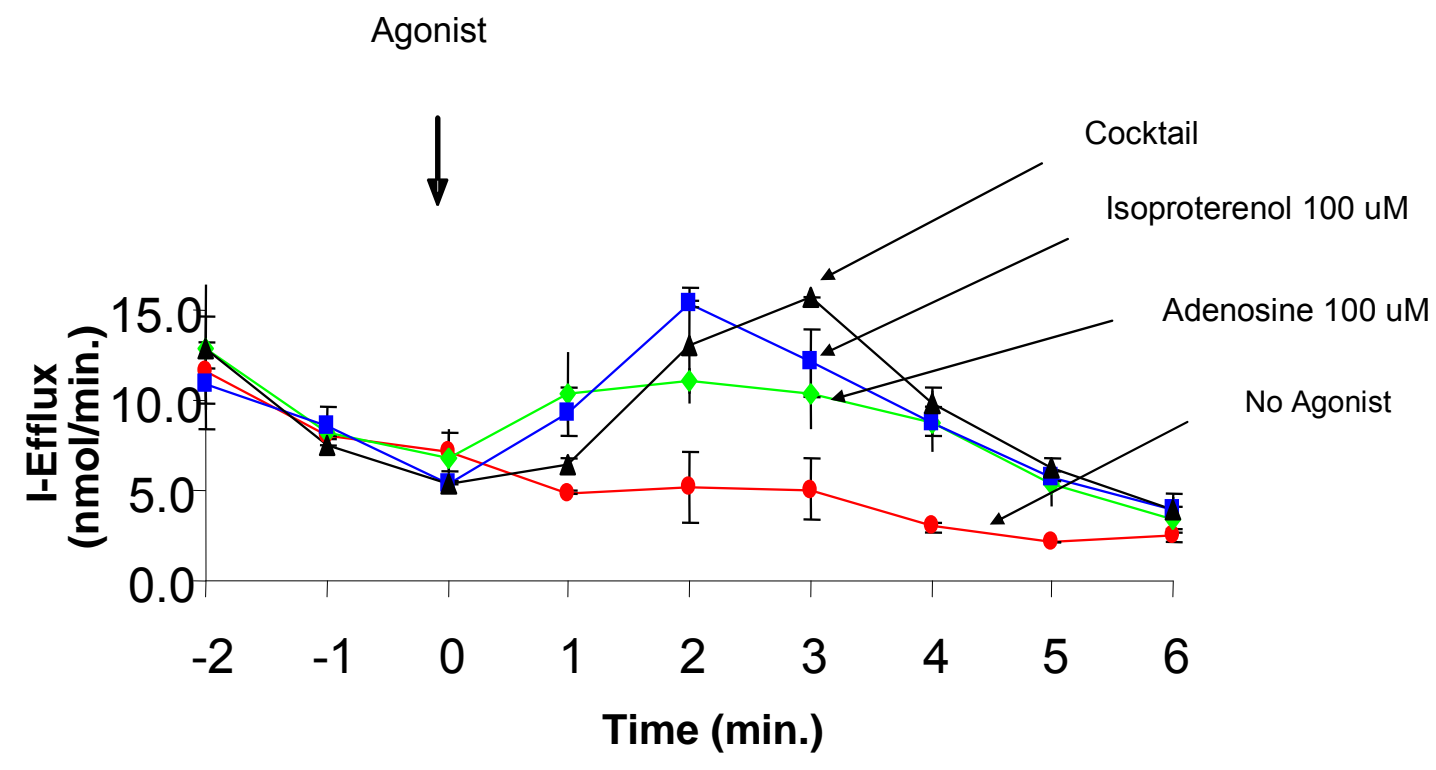

Figure 2-5. HEK-293-Flag-CFTR Cells Respond to CFTR Activating Agonists 


\section{Mass Spectrophotometric Identification of CFTR}

It is expected that sufficient quantities of Flag-CFTR can be purified to confirm the protein identity via mass spectrometry. Flag-CFTR lysate was incubated overnight with anti-flag antibody beads. The lysate with then eluted and protein concentration was determined. Purified CFTR protein ( $\sim 6 \mu \mathrm{g} /$ lane) was subjected to $4-15 \%$ SDSpolyacrylamide gel electrophoresis (PAGE) and stained with Coomassie blue (Figure 2-6). The band of interest was excised, trypsin digested, and extracted using ZipTip C18 microcolumns. Proteins were eluted with 50\% acetonitrile, dried, and redissolved in 4 $\mu \mathrm{L}$ of $0.1 \%$ Trifluoroacetic acid (TFA) in water. Chromatography of the sample was performed using a linear gradient of increasing acetonitrile at a flow rate of 400 nanoliter $(\mathrm{nL}) /$ minute and sprayed into the mass spectrometer. Three types of spectra were acquired: a full-scan of the mass spectrum, a zoom scan of the two most prominent ions, and MS/MS scans of the two most prominent ions. Spectra were analyzed by SEQUEST software and scored using a MOWSE scoring algorithm. Anything above a score of 65 is considered significant and a positive identification of the protein sample. Four peaks were positively identified as CFTR with MOWSE scores as high as $\sim 135$. Thus, the peptide peaks were positively identified as human CFTR (Figure 2-7). 


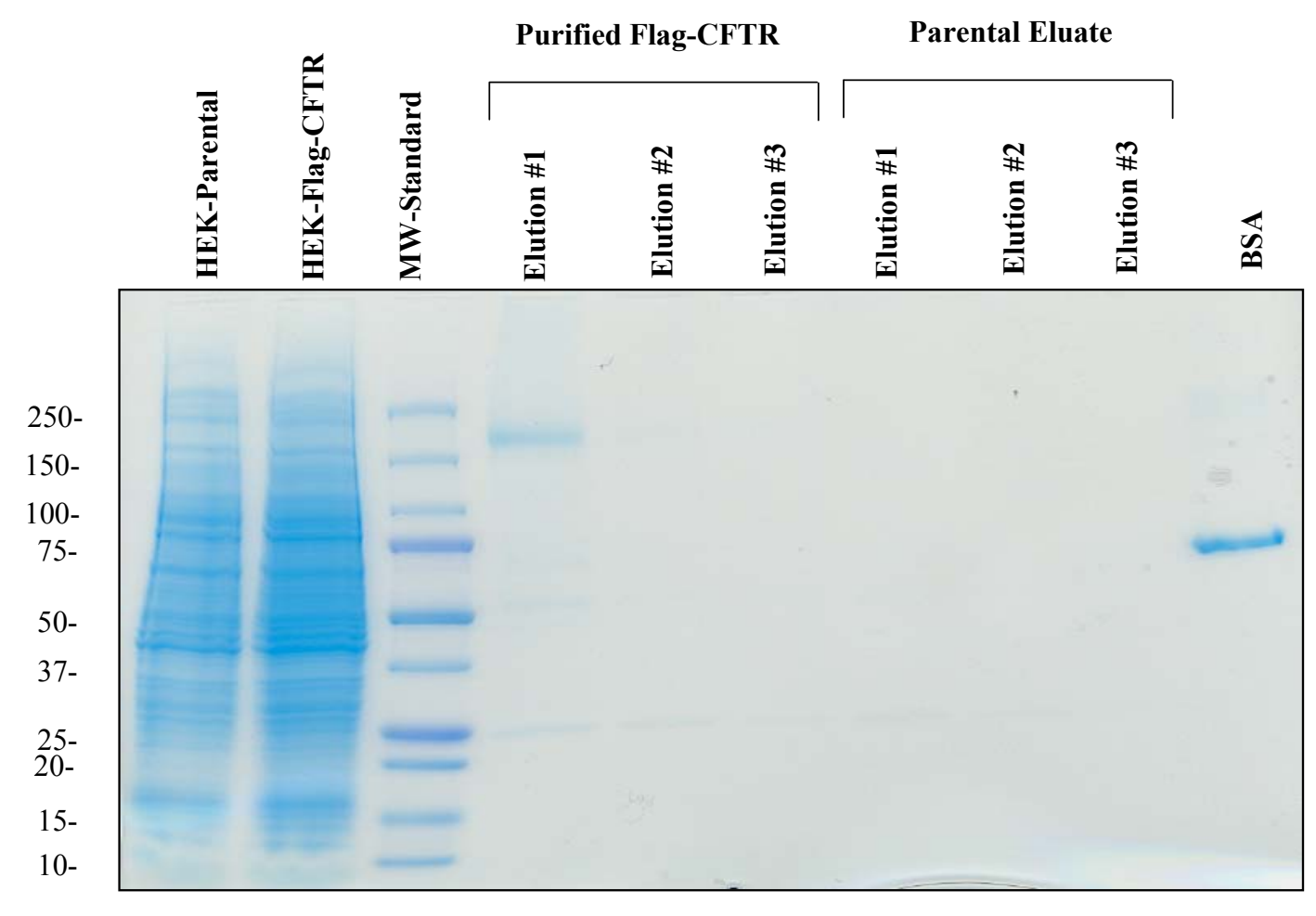

Figure 2-6. Purification of Flag-CFTR 


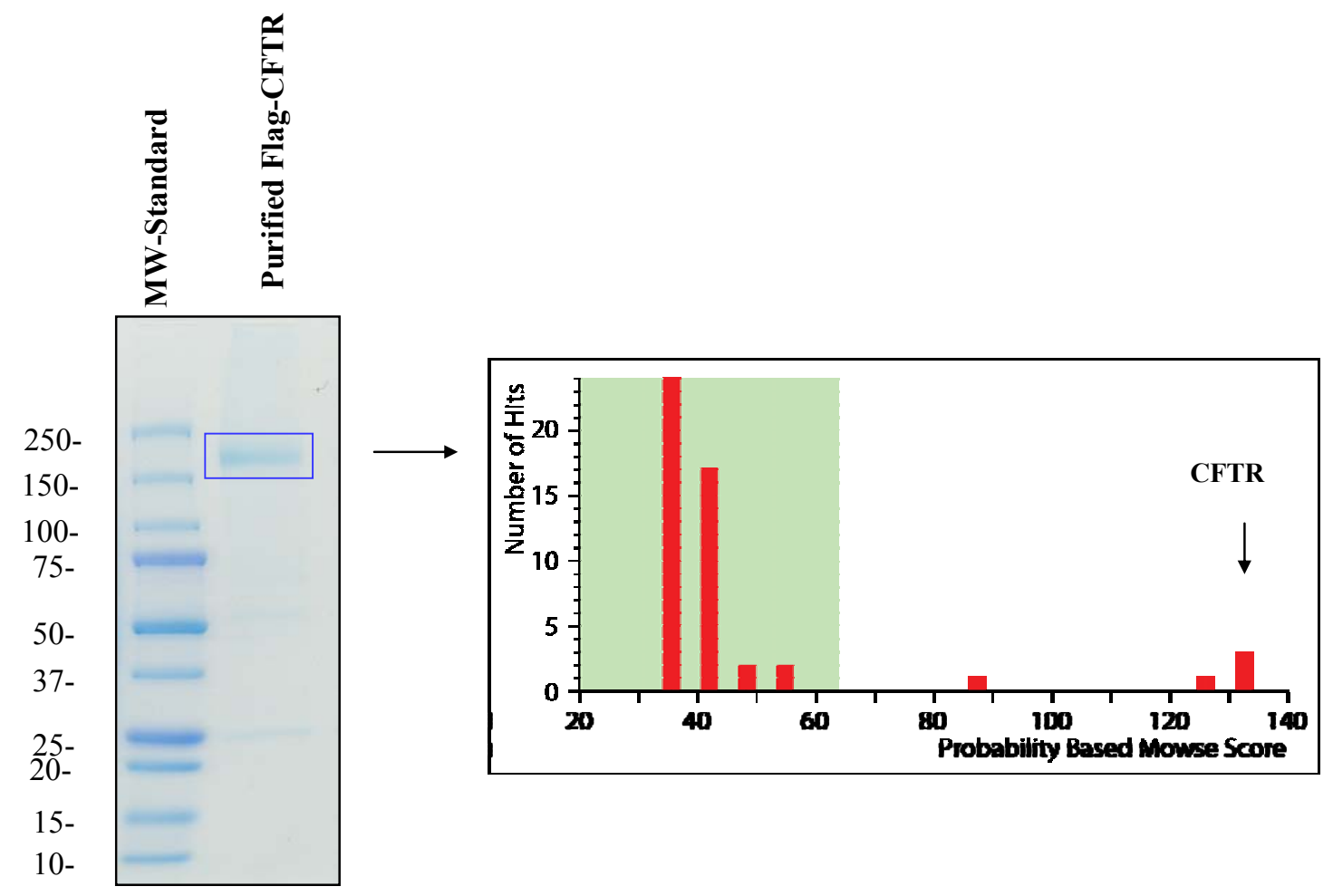

Figure 2-7. Mass Spectrometry: Identification of Flag-CFTR 


\section{CHAPTER 3: HSP-90 AND CFTR: ASSOCIATION AND FUNCTIONAL INTERACTION}

\section{Materials and Methods}

\section{Coimmunoprecipitation and Immunoblotting}

Dithiobis(succinimidyl)propionate (DSP) $[1 \mathrm{mM}]$ was prepared by initially solubilizing in $40 \mu \mathrm{L}$ of DMSO, followed by addition of $10 \mathrm{~mL}$ of PBS warmed to $37^{\circ} \mathrm{C}$. HEK-Flag-CFTR cells were cross-linked with (DSP) $[1 \mathrm{mM}]$ for 10 minutes at $37^{0} \mathrm{C}$. Cells were then solubilized in modified radioimmunoprecipitation (RIPA) buffer ( $\mathrm{NaCl}$ 140 mM, Nonidet P40 (NP40) 1\%, Na-deoxycholate $0.5 \%$, sodium dodecyl sulfate (SDS) $0.1 \%$, Tris- $\mathrm{HCl} 50 \mathrm{mM}, \mathrm{pH} 8.0$ ) plus protease inhibitors on ice for $20 \mathrm{~min}$, and lysates were spun at $15,000 \mathrm{~g}$ for $15 \mathrm{~min}$ at $4^{\circ} \mathrm{C}$ to pellet insoluble material. $40 \mu \mathrm{g}$ of the clarified protein lysate (protein was estimated using the dye binding method. Anti-Flag beads were incubated with the cross-linked supernatant overnight at $4^{\circ} \mathrm{C}$ with constant mixing on a rotator. After washing the beads three times with RIPA buffer, the cross-linked proteins were eluted with sample buffer. During this process, the $2.5 \%$ ßmercaptoethanol cleaved the S-S bond of the DSP, separating the proteins. The immunoprecipitated proteins were separated on 4-15\% gel. For western blotting, proteins were transferred to a polyvinylidene difluoride (PVDF) membrane and blotted using $\alpha$-CFTR monoclonal antibody (R1104) and $\alpha$-Hsp-90 monoclonal antibody (Hsp90/F8). 


\section{Protein Purification}

HEK-Flag-CFTR cells were lysed PBS $0.2 \%$ Triton X-100 with protease inhibitors (aprotenin $[1 \mu \mathrm{g} / \mathrm{mL}]$, leupeptin $1 \mu \mathrm{g} / \mathrm{mL}$, pepstatin $1 \mu \mathrm{g} / \mathrm{mL}$, PMSF [400 $\mu \mathrm{M}]$ ). The lysate is centrifuged at $16,000 \mathrm{~g}$ for $10 \mathrm{~min}$ at $4^{\circ} \mathrm{C}$. Then, immunoprecipitation is performed on the pre-cleared lysate overnight at $4 \mathrm{oC}$ while rotating using Flag antibody conjugated beads (Seize Immunoprecipitation Kit, Pierce Chem. Co.). The proteins are then bound to spin columns, spun for [insert] minutes at 3,000 $\mathrm{g}$ and washed with lysis buffer. Immunoprecipitated material eluted from beads using 100mM Glycine $\mathrm{pH} 2.2$ (0.2\% Triton) into $1.5 \mathrm{M}$ Tris $(\mathrm{pH} 8.8)$. The eluted protein was then was separated on a 4-15\% SDS polyacrylamide gel (SDS-PAGE) and visualized with Gel Code Blue (Pierce.)

\section{Short-Circuit Current Assay}

Calu-3 cells were grown to confluency as polarized monolayers on Costar Transwell permeable supports with a filter area of $0.33 \mathrm{~cm}^{2}$. Short-circuit current measurements were recorded after mounting filters in an Ussing chamber as previously described (Li, C, et al. 2004). Epithelia were maintained at $37{ }^{\circ} \mathrm{C}$ and gassed with $95 \%$ $\mathrm{O}_{2}$ and $5 \% \mathrm{CO}_{2}$ while being bathed in low $\mathrm{Cl}^{-}$Ringer's solution on the apical side of the monolayer (mM): (133.3 Na-gluconate, $5 \mathrm{~K}$-gluconate, $2.5 \mathrm{NaCl}, 0.36 \mathrm{~K}_{2} \mathrm{HPO}_{4}, 0.44$ $\mathrm{KH}_{2} \mathrm{PO}_{4}, 5.7 \mathrm{CaCl}_{2}, 0.5 \mathrm{MgCl}_{2}, 4.2 \mathrm{NaHCO}_{3}, 10$ Hepes, 10 mannitol, pH 7.2, [Cl] = 14.8) and normal Ringer's solution basolaterally (mM): $\left(140 \mathrm{NaCl}, 5 \mathrm{KCl}, 0.36 \mathrm{~K}_{2} \mathrm{HPO}_{4}, 0.44\right.$ $\mathrm{KH}_{2} \mathrm{PO} 4,1.3 \mathrm{CaCl}_{2}, 0.5 \mathrm{MgCl}_{2}, 4.2 \mathrm{NaHCO}_{3}, 10$ Hepes, 10 glucose, $\mathrm{pH} 7.2,\left[\mathrm{Cl}^{-}\right]=$ 149). Radicicol [1 mM] was added to the apical and serosal sides of the cell monolayers 
for 30 minutes prior to addition of apical isoproterenol. In parallel, filters were also incubated without Radicicol before isoproterenol addition as a control. DPC (CFTR $\mathrm{Cl}^{-}$ channel inhibitor) was added to the apical side of the monolayer at the end of the experiment. A 2-mV pulse was applied to the epithelia every minute throughout the experiment to monitor the integrity of the epithelia.

Airway Fluid Clearance (AFC) Measurement

C57BL/6 mice are instilled with albumin (Evan's blue tagged) in an isoosmolar (324 mOsm) instillate. Alveolar instillate was administered with and without Radicicol $[1 \mu \mathrm{M}]$. Temperature of mice is maintained at $37{ }^{\circ} \mathrm{C}$ using a heating pad and lamp. After a 30-min period, the alveolar fluid is aspirated. AFC, expressed as a percentage of total instilled volume, is calculated using the BCA protein assay (Pierce, Rockford, IL). Radicicol sensitivity is reported as percent reduction AFC compared to control (Ethanol) treated mice. Rate of fluid removal from the alveolar airspace (alveolar fluid clearance) was determined by a modification the procedure described by Factor (Factor, Mutlu et al. 2007).

\section{Two-Electrode Voltage Clamp Recordings}

Oocyte currents were acquired using standard two-electorde voltage clamp techniques. I/V relationships are obtained from oocytes uninjected, water injected (46 nanoliter (nL), or injected with wtCFTR complementary ribonucleic acid (cRNA) (5 nanograms (ng)/46nL). During recording conditions, oocytes were incubated with that were in $\mathrm{Ca}^{2+}$ free ND96 containing 8-(4-chlorophenylthio) cAMP (cpt.cAMP) [200 uM], 
Forskolin [10 uM], and IBMX [100 uM]. Steady current levels averaged over the last half of $75 \mathrm{~ms}$ voltage steps from -80 to $+60 \mathrm{mV}$ in $10 \mathrm{mV}$ increments are plotted against voltage. Currents were acquired using an Axon Instruments GeneClamp 500B amplifier and pClamp software Version 9.2 (Molecular Devices, Union City, CA) at a corner frequency of 500 hertz $(\mathrm{Hz})$. Borosilicate glass was used to pull electrodes (Sutter Instruments; Novato, CA). Pipettes were filled with $3 \mathrm{M}$ potassium chloride $(\mathrm{KCl})$ and had a resistance of 0.5-2.0 mega ohms (MOhms). Recording solution was $\mathrm{Ca}^{2+}$-free oocyte recording solution (ND96) containing: $96 \mathrm{mM} \mathrm{NaCl}, 2 \mathrm{KCl}, 1 \mathrm{mM}$ magnesium chloride $\left(\mathrm{MgCl}^{2}\right)$, and $5 \mathrm{mM}$ 4-(2-hydroxyethyl)-1-piperazineethanesulfonic acid (HEPES). Membrane voltages were held at -45 millivolts $(\mathrm{mV})$ and stepped to a series of potentials between $-80 \mathrm{mV}$ and $+60 \mathrm{mV}$. For construction of current-voltage $(I-V)$ curves, data were averaged from the latter half of a 75-millisecond (ms) step to each potential. Conductance was calculated from linear fits to the steady currents between - 60 and $-40 \mathrm{mV}$. Average conductance values were from $4-5$ oocytes and reported as mean (+/- SEM) (McCarty, McDonough et al. 1993; Chan, Csanady et al. 2000; McCarty and Zhang 2001).

\section{Results}

\section{Hsp90 Association with CFTR}

In a recent study published from our laboratory, it was shown that WT CFTR exists in cells as a high molecular weight complex as determined by a cross-linking method (Li, Roy et al. 2004). Several reagents have the capability to affinity cross-link 
CFTR in its macromolecular complex. One of the crosslinking reagents (DSP) is cell permeant, an excellent crosslinker, and has a disulphide bond (S-S) that is cleaved in the presence of $5 \% \beta$-mercaptoethanol ( $\beta$-ME). Upon cross-linking the cells (see materials and methods), a band of a higher order complex greater than $250 \mathrm{kDa}$ was observed as predicted for the CFTR macromolecular complex with its interacting partners. Furthermore, when cross-linked with DSP and analyzed by SDS-PAGE in the presence of $5 \% \beta-\mathrm{ME}$, the $150 \mathrm{kDa}$ band could be resolved yielding a large amount of protein appearing to be of sufficient quantity for mass spec analysis (Figure 3-1).

Several cross-linking reagents were tested to determine their effect on the crosslinking of HSP-90 to CFTR. The cells were incubated with one of three cross-linking reagents which are cleavable by $5 \% \beta$-ME; DSP, dimethyl 3, 3' dithiobispropionimidate$2 \mathrm{HCl}$ (DTBP), and 1, 4-di-[3'-(2'-pyridyldithio)-propionamido] butane (DPDPB) (1 $\mathrm{mM})$. The cells were lysed in RIPA buffer and immunoprecipitated with the anti-FLAG anti-body and probed for HSP-90. All three detected some amount of protein, the most being detected by DPDPB and DSP (Figure 3-2).

To determine if the binding of CFTR to heat shock proteins is specific for HSP90, the cross-linked complex was probed for both HSP-90 and HSP-70. The cells were lysed with Tris-base saline (TBS) containing $0.2 \%$ Triton-X-100 (TBS $-0.2 \%$ TX-100). Whereas RIPA breaks most protein-protein interactions, TBS-0.2\% TX-100 does not. This is due to the presence of SDS and $\mathrm{Na}$-deoxycholate in RIPA buffer, which disrupts protein-protein interactions and is useful in solubilizing integral membrane proteins. Using parental HEK cells as a control, it is observed that HSP-90 increases in the macromolecular complex upon cross-linking while HSP-70 does not (Figure 3-3). 


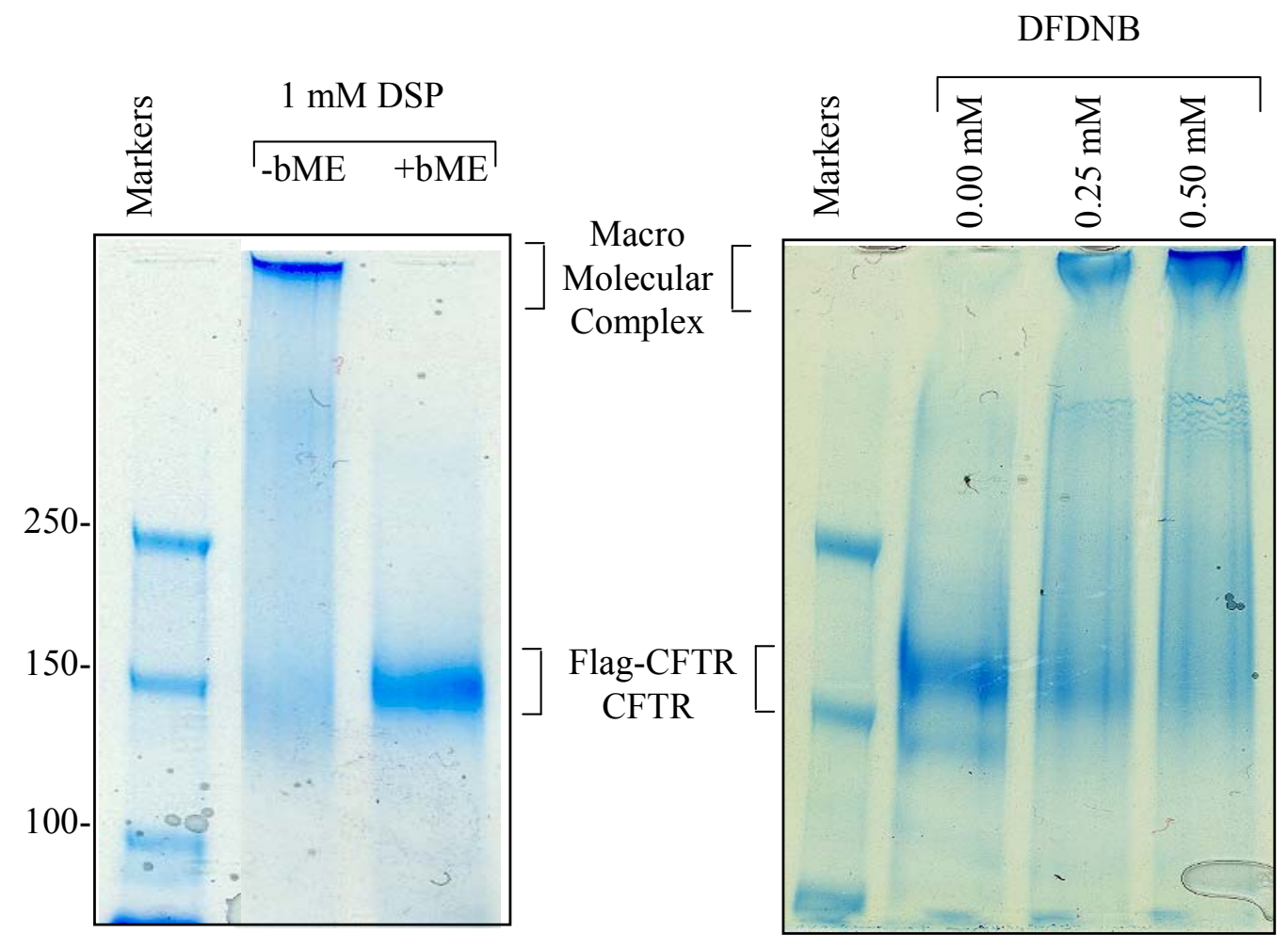

Figure 3-1. CFTR Macromolecular Complex 
INPUT (5\%)

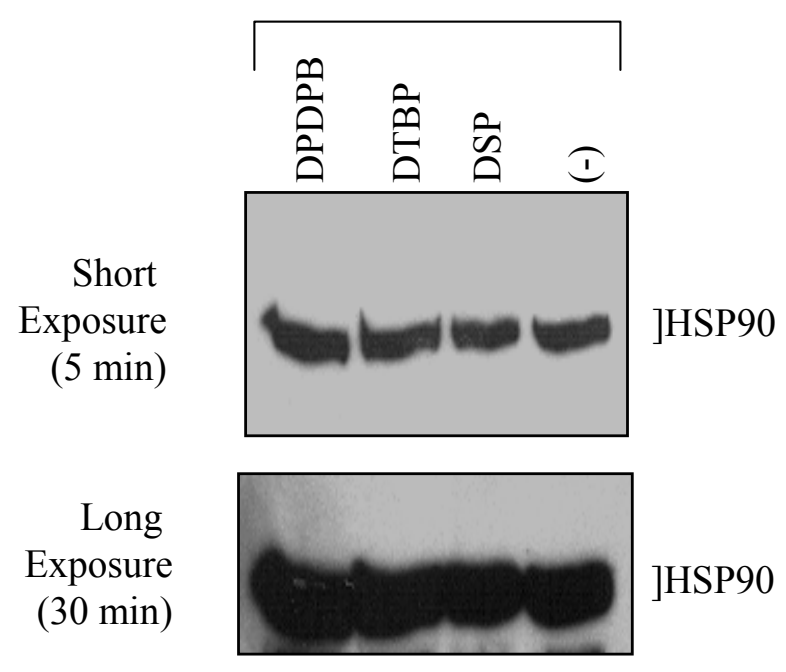

CO-IP (a-Flag-CFTR)

(RIPA-buffer)

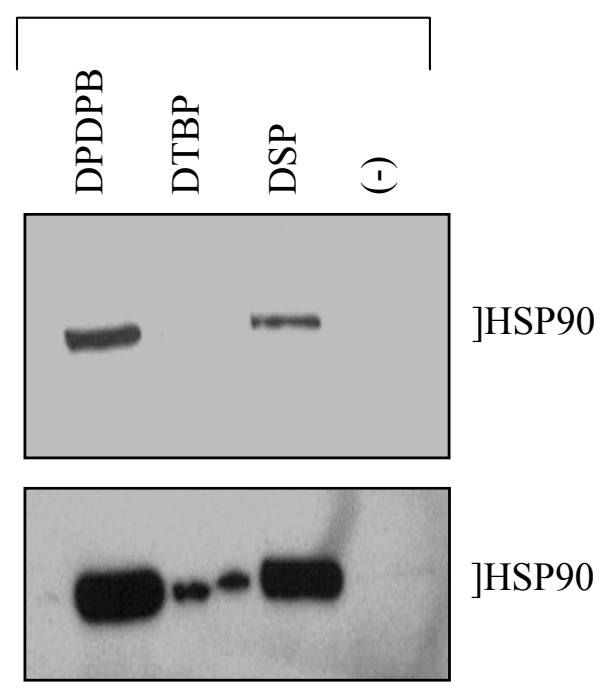

Figure 3-2. Hsp90 Associates with CFTR 

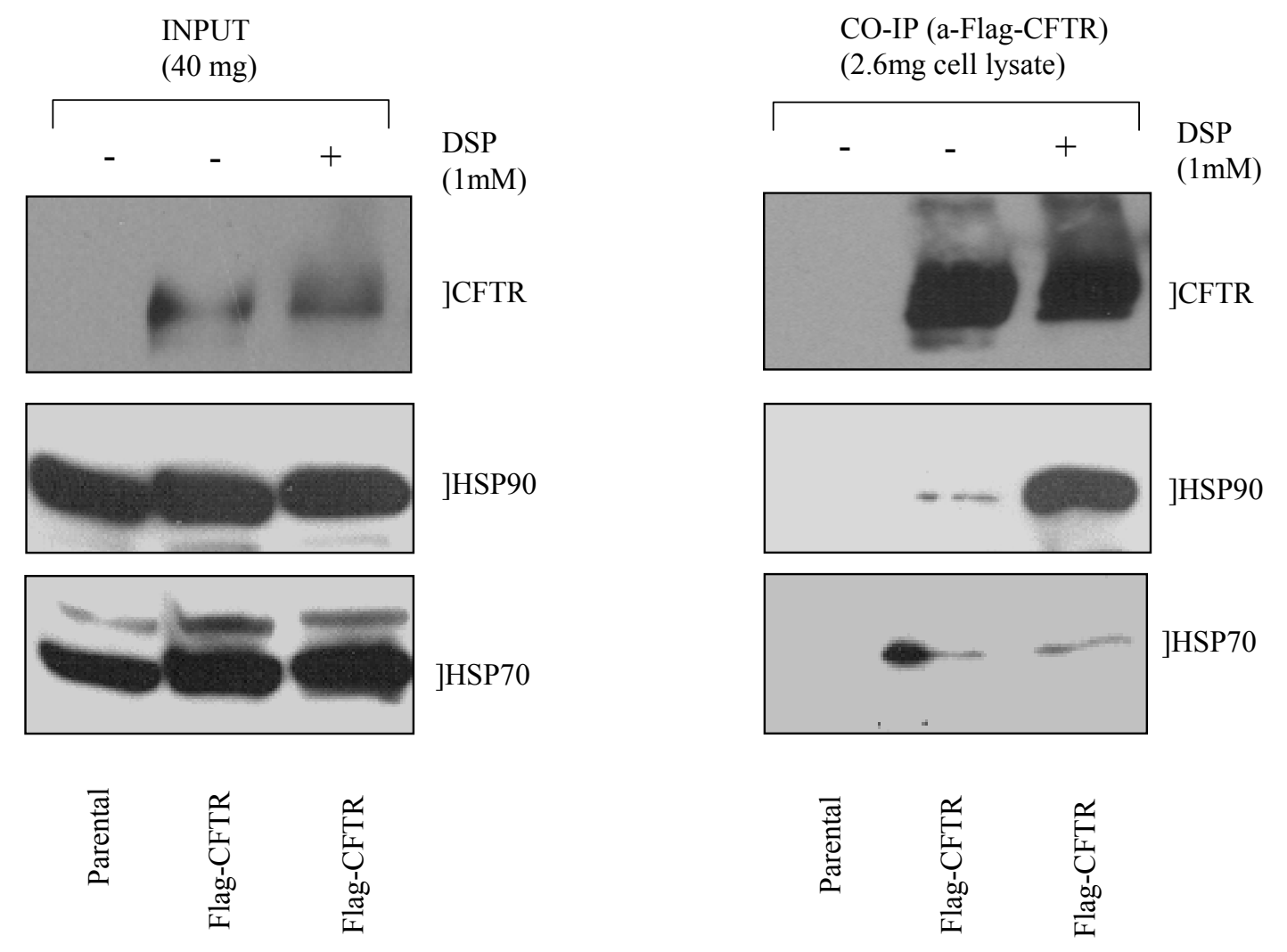

Figure 3-3. Hsp-90 Specific Association with CFTR 


\section{Hsp90 Mass Spectrometry}

To identify interacting partners in the macromolecular complex, cross-linking with DSP $\left(1 \mathrm{mM}\right.$ for $10 \mathrm{~min}$ at $\left.37^{\circ} \mathrm{C}\right)$ was performed, the proteins were subjected to 415\% SDS-PAGE, and the gel was stained with Coomassie Brilliant Blue stain. Approximately $2 \mu \mathrm{g}$ of protein was loaded per lane. A $90 \mathrm{kDa}$ band was identified in the macromolecular complex. The band of interest was excised, trypsin digested, and extracted using ZipTip C18 microcolumns. Proteins were eluted with 50\% acetonitrile, dried, and redissolved in $4 \mu \mathrm{L}$ of $0.1 \%$ Trifluoroacetic acid (TFA) in water. Chromatography of the sample was performed using a linear gradient of increasing acetonitrile at a flow rate of 400 nanoliter $(\mathrm{nL}) /$ minute and sprayed into the mass spectrometer. Three types of spectra were acquired: a full-scan of the mass spectrum, a zoom scan of the two most prominent ions, and MS/MS scans of the two most prominent ions. Spectra were analyzed and scored using a MOWSE scoring algorithm. Anything above a score of 65 is considered significant and a positive identification of the protein. When subjected to MALDI-TOF mass spectrometry, 27 peaks were positively identified as HSP-90 with a MOWSE score as high as 235 (Figure 3-4). Thus, the $90 \mathrm{kDa}$ band cross-linked to CFTR is shown to be Hsp90.

\section{Hsp90 Augmentation of CFTR Chloride Transport}

The Xenopus oocyte protein expression system is a well established tool for assessing CFTR function and proteins that regulate CFTR activity (Gurdon, Lane et al. 1971; Bossi, Fabbrini et al. 2007) . Two of the characteristics of CFTR currents are that they display a linear current-to-voltage (I/V) relationship and that can be inhibited by 


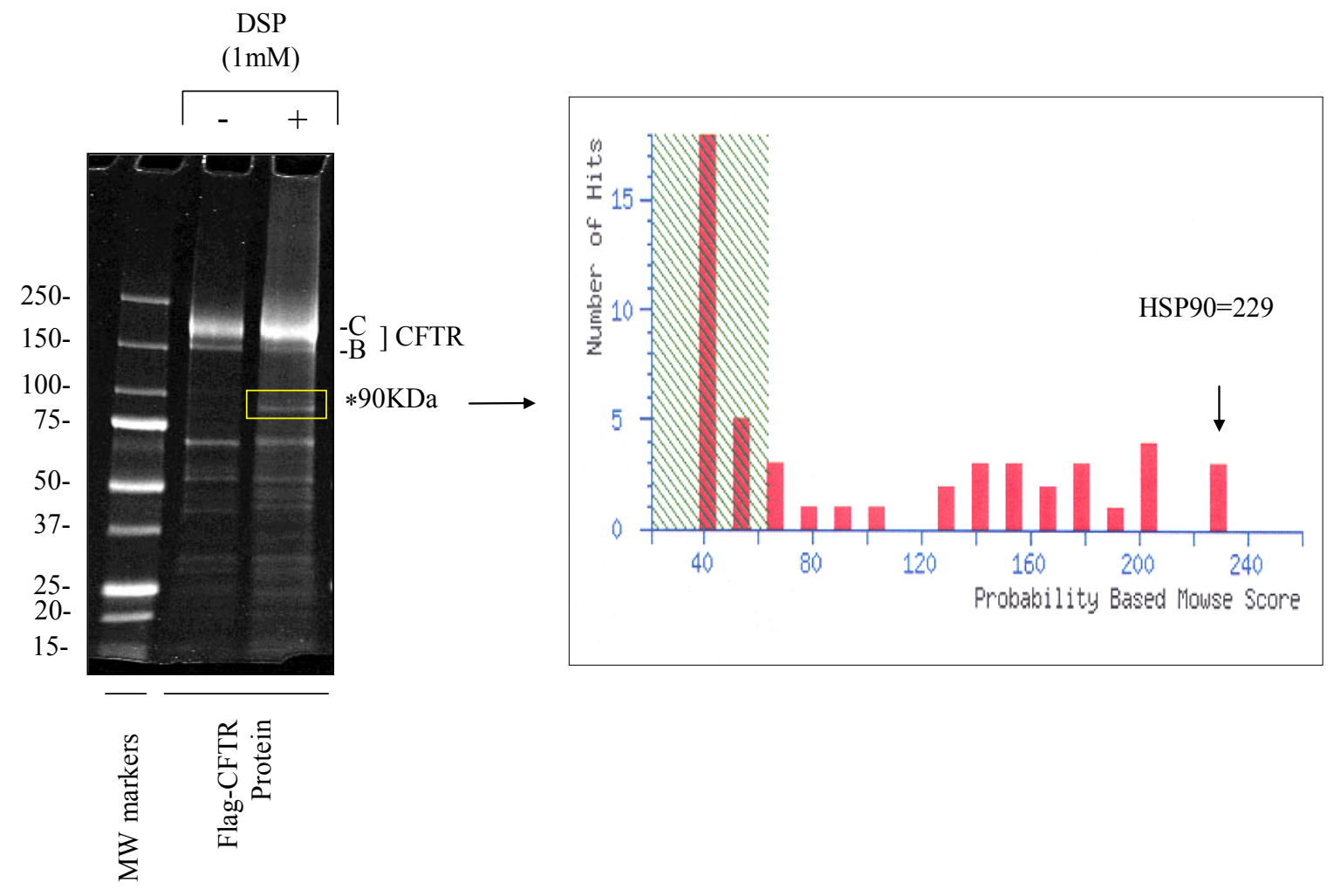

Figure 3-4. Mass Spectrometry: Identification of Hsp90 
DPC (McCarty, McDonough et al. 1993). As expected, I/V relationships were approximately linear and showed roughly the same reversal potential both before and during agonist activation (Figure 3-5). Also, diphenylamine carboxylate (DPC) [500 uM] reduced the conductance across the oocyte membrane by $28.3 \%$ (without DPC $=99.6 \mathrm{pS}$; with $\mathrm{DPC}=28.2 \mathrm{pS}$ ) Negative voltages were reduced while positive voltages remained unaffected as previously reported (Figure 3-6) (Naren, Nelson et al. 1997; Naren, Quick et al. 1998). It is expected that if Hsp90 is regulating CFTR function, this interaction should be detectable in the Xenopus oocyte expression system. Oocytes were injected with either full length HSP-90 or bovine serum albumin (BSA) (80 ng protein each) and recorded 30-120 minutes later (Naren, Nelson et al. 1997). Full-length HSP-90, but not BSA, increased CFTR chloride conductance by 28 pS (Figure 3-7). Injected oocytes displayed linear current-voltage behavior and were blocked by DPC as in Figure 3-5. HSP-90 and BSA did not change linear I/V behavior or reversal potential. Conductance was calculated from linear fits to the steady currents between -60 and $-40 \mathrm{mV}$. As anticipated, Hsp90 increases CFTR chloride conductance while BSA has no effect.

\section{Radicicol Inhibits Chloride Transport}

To extend our results and examine the effect of Hsp90 in a more physiologically relevant system, we used the Ussing Chamber system. This assay allows for the measurement of chloride currents across a polarized epithelial monolayer grown on permeable supports. In these experiments, Calu-3 cells were used to determine the effect of Hsp90 on CFTR chloride transport. Calul-3 cells are human submucosal epithelial cells derived from lung adenocarcinoma. They abundantly express endogenous CFTR, 


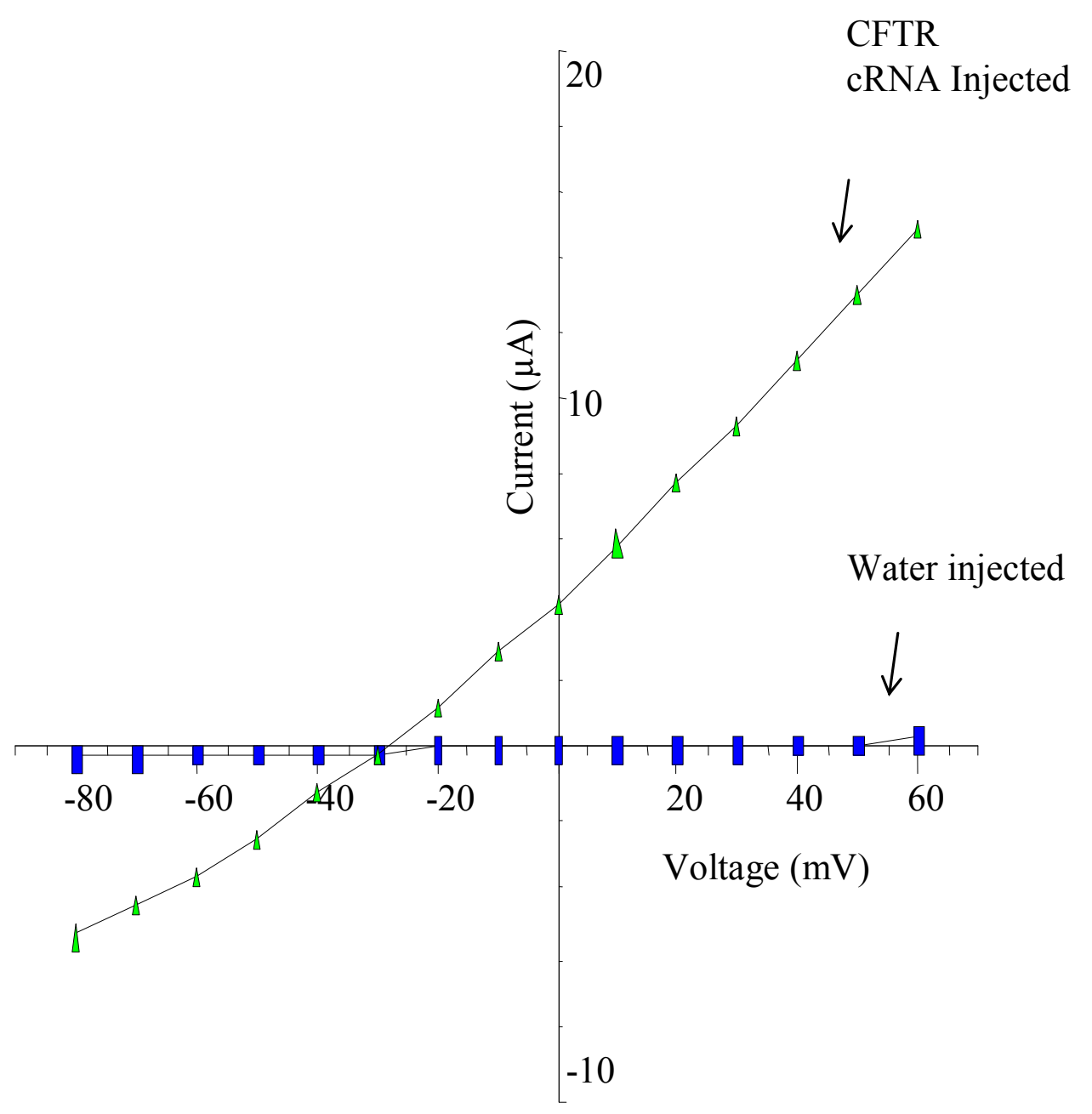

Figure 3-5. Expression of CFTR cRNA in Xenopus Oocytes 


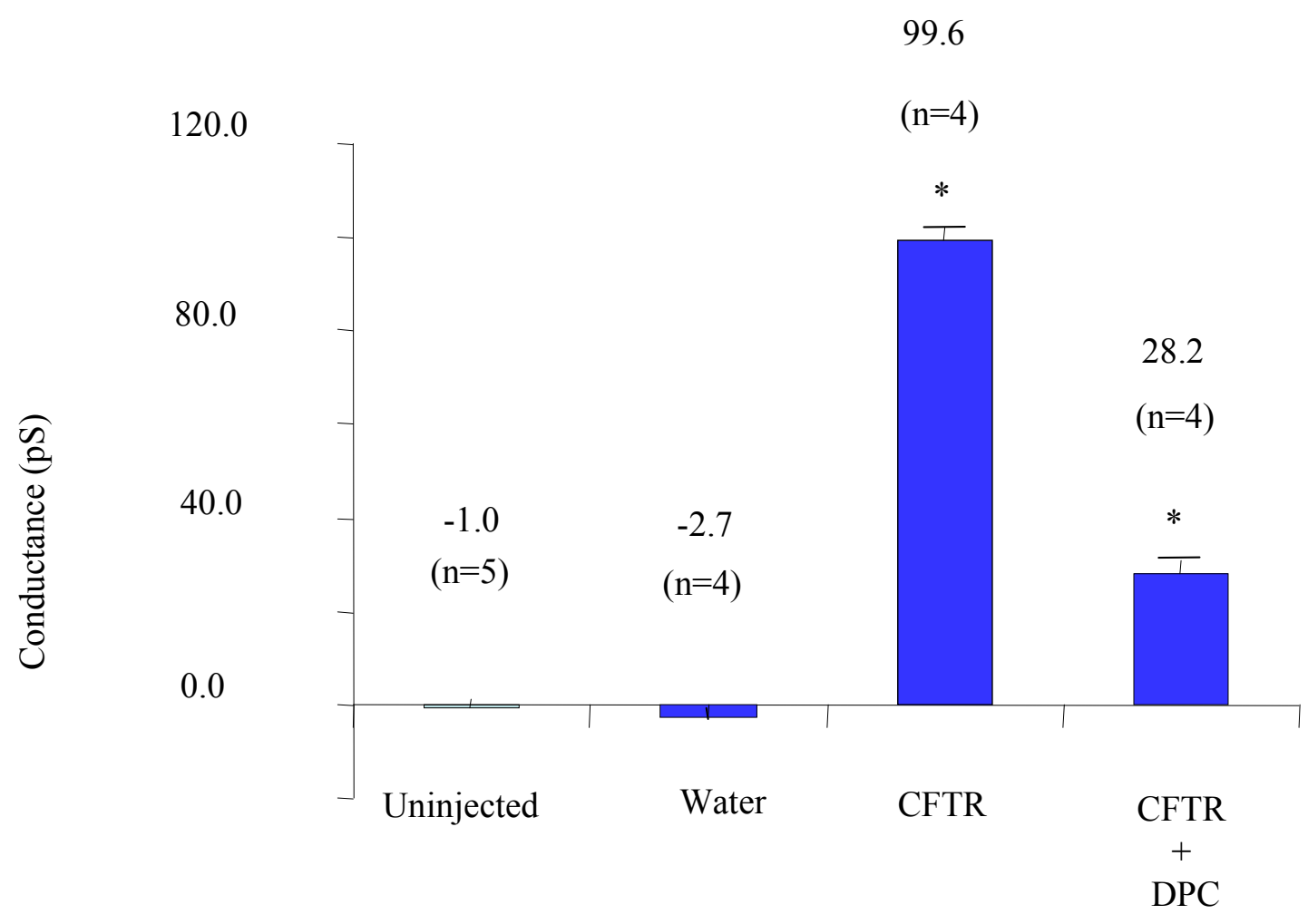

Figure 3-6. Inhibition of CFTR in Xenopus Oocytes by DPC 


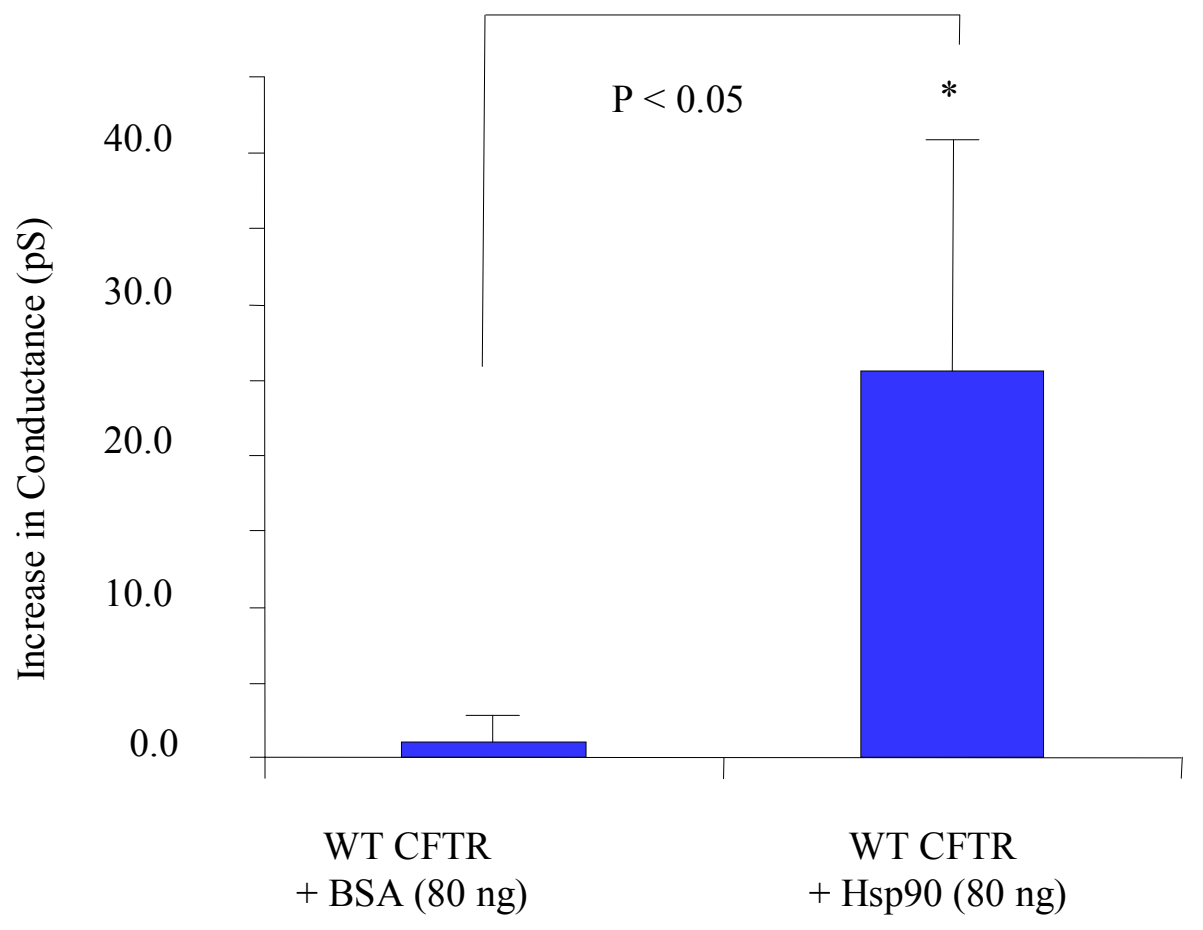

Figure 3-7. HSP-90 Increases CFTR Conductance in Xenopus Oocytes 
form tight junctions and polarized epithelial monolayers, and will exhibit CFTR dependent $\mathrm{Cl}^{-}$secretion in response to $\mathrm{B}_{2}-\mathrm{AR}$ receptor activation (Haws, Finkbeiner et al. 1994; Naren, Cobb et al. 2003; Li, Dandridge et al. 2005). It is expected that, if Hsp90 is having a positive effect on CFTR function, inhibiting Hsp90 with radicicol should decrease CFTR activity. As expected, measurements taken in this system show an increase in $\mathrm{Cl}^{-}$flux in response to increasing concentrations of Isoproterenol $[10 \mathrm{~nm}-10$ $\mathrm{uM}$ ] approaching a near maximal response. The currents could be inhibited with $500 \mathrm{uM}$ DPC, indicative of CFTR chloride channel activity. When the monolayers were pretreated for approximately 30 minutes with radicicol (RD), a specific inhibitor of Hsp90 with nanomolar affinity, the maximal $[10 \mathrm{uM}]$ isoproterenol short-circuit current response $\left(\sim 86 \mu \mathrm{A} / \mathrm{cm}^{2}\right)$ was decreased by $29 \%$ (Figure 3-8).

\section{Radicicol Inhibition of in vivo Chloride Transport}

To confirm our studies further establish physiological significance, the effect of Hsp90 inhibition was assessed on airway fluid clearance in C57BL/6 mice. It is expected that if Hsp90 is inhibiting CFTR, than airway fluid clearance, a process dependent on CFTR (Mutlu, Adir et al. 2005) should decrease in the presence of radicicol. Mice used

in the airway fluid clearance assay (see materials and methods) showed a maximal airway fluid clearance rate under control conditions $[0.1 \%$ ethanol] that was significantly reduced under conditions in which the mice were treated for 30 minutes with a specific inhibitor of Hsp90 [1 uM Radicicol] (Figure 3-9). The temperature of the mice is maintained at $37^{\circ} \mathrm{C}$ using a heating pad and lamp throughout the experiment. 


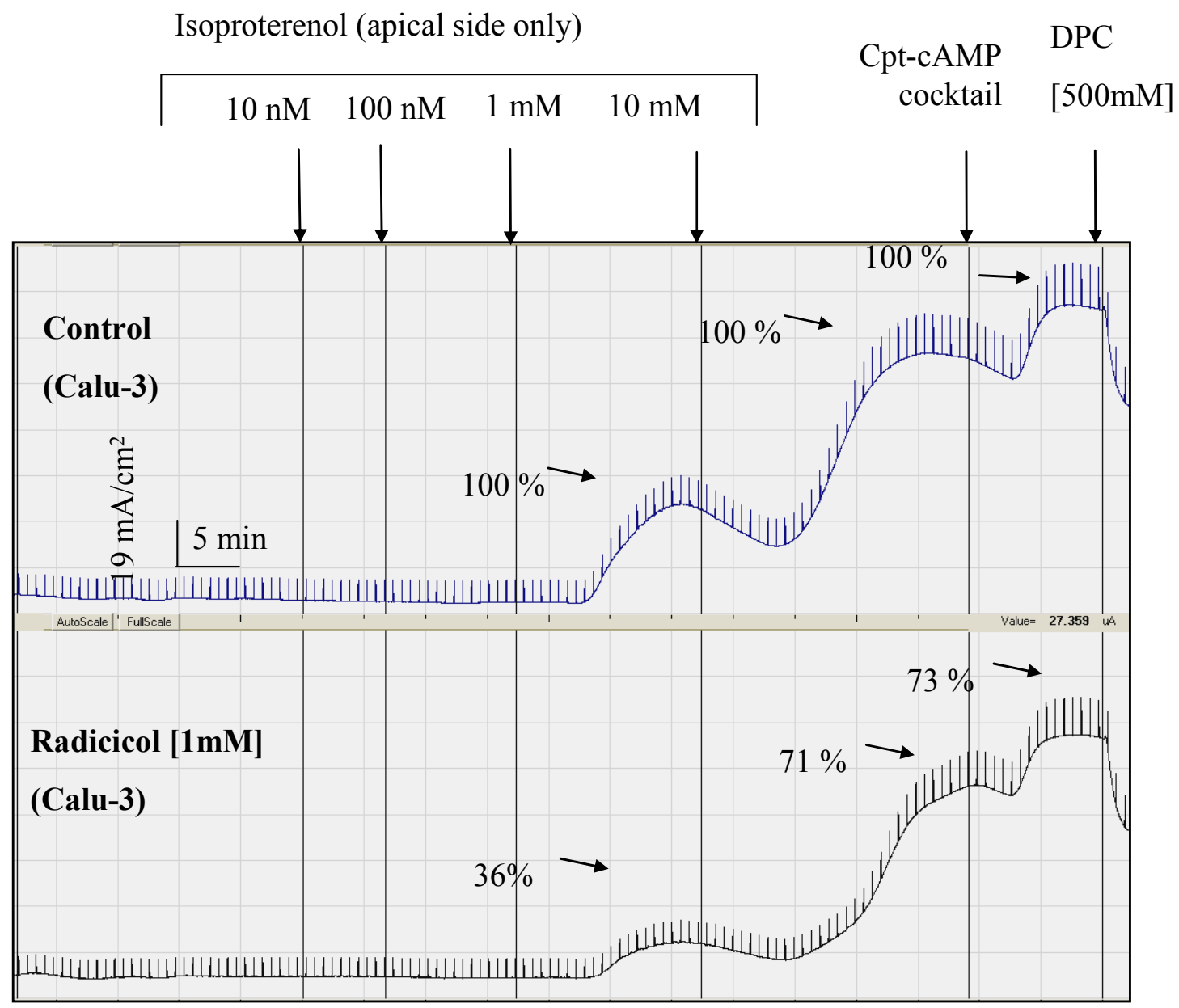

Figure 3-8. Radicicol Inhibits CFTR-Mediated Short-Circuit Currents 


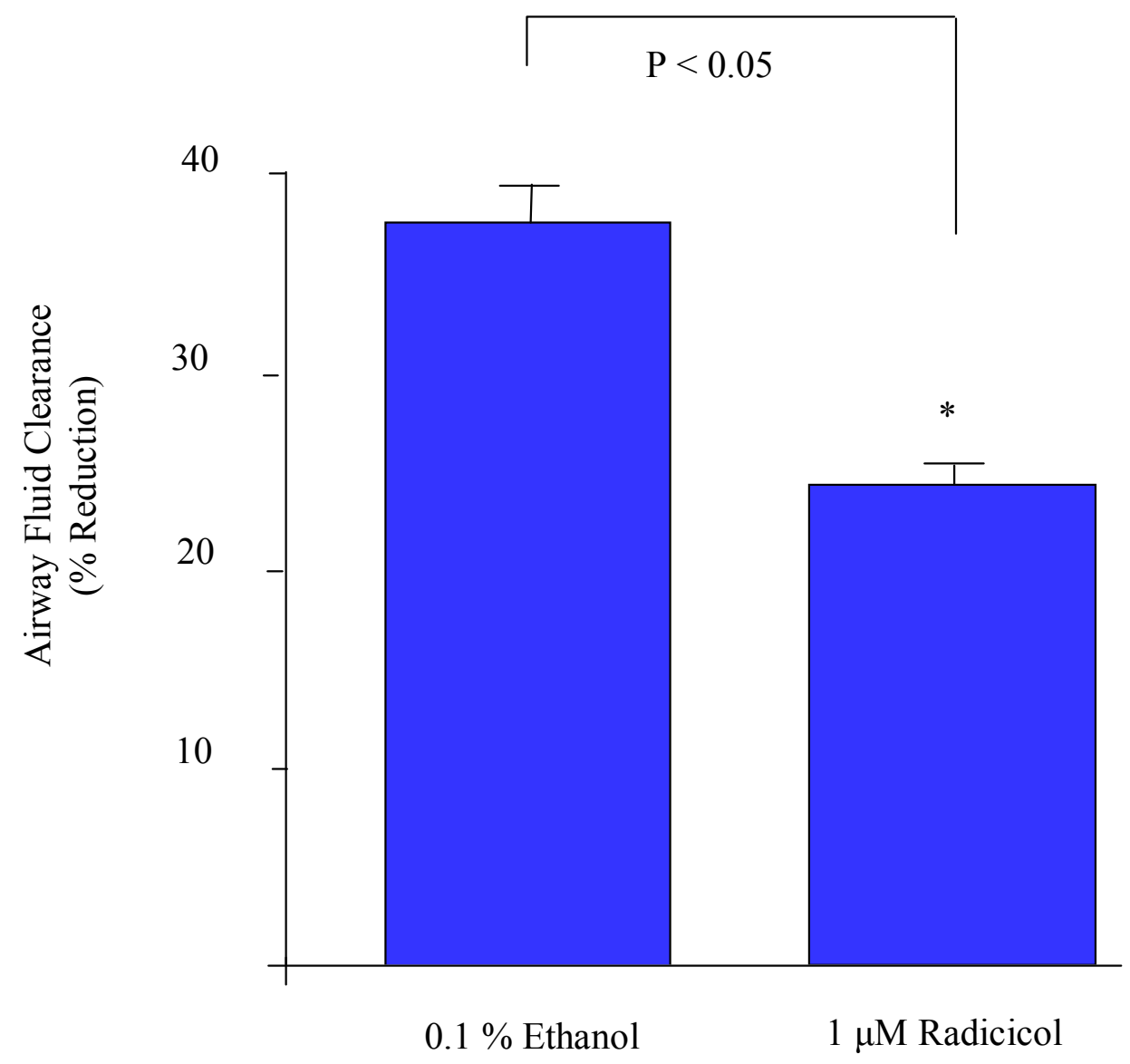

Figure 3-9. Radicicol Inhibits in vivo Airway Fluid Transport in C57BL/6 Mice 


\section{Hsp90 Association Increases CFTR Phosphorylation}

To determine if the interaction between HSP-90 and CFTR is regulated by the $\beta$ adrenergic receptor signaling pathway, the effect of Hsp90 on CFTR phosphorylation was determined. CFTR is phosphorylated by PKA in response to $\beta$-agonist-mediated activation of the $\beta_{2}$-AR. The ability of a PKA-substrate antibody to detect CFTR was first tested (see materials and methods). Increasing amounts of purified Flag-CFTR was incubated with the catalytic subunit of PKA (cPKA). Conversely, increasing amounts of cPKA (0-200 units $/ \mathrm{mL})$ were incubated with $500 \mathrm{ng}$ of purified CFTR. Under both conditions, the PKA substrate antibody detected an increased amount of phosphorylated CFTR (Figure 3-10).

If Hsp90 is involved in cPKA-mediated phosphorylation of the CFTR, then by increasing the amounts of Hsp90-CFTR complexes, this should result in increased phospho-CFTR in these complexes. It was observed that by increasing the concentrations of DSP, a greater proportion of the total CFTR in the complex was phosphorylated, perhaps because of increasing Hsp90-CFTR complexes in the immunoprecipitations. Furthermore, with increasing amounts of DSP, an increase in the amount of HSP-90 was observed in the complex (Figure 3-11). This indicates that HSP90 may play a role in the PKA regulation of CFTR function.

\section{Radicicol Inhibits CFTR Phosphorylation}

To test if HSP-90 may be playing a role in PKA phosphorylation of CFTR, and therefore possibly CFTR function, the effect of Radicicol (RD) was determined. With increasing concentrations of $\mathrm{RD}$, the amount of phosphorylated CFTR decreased 


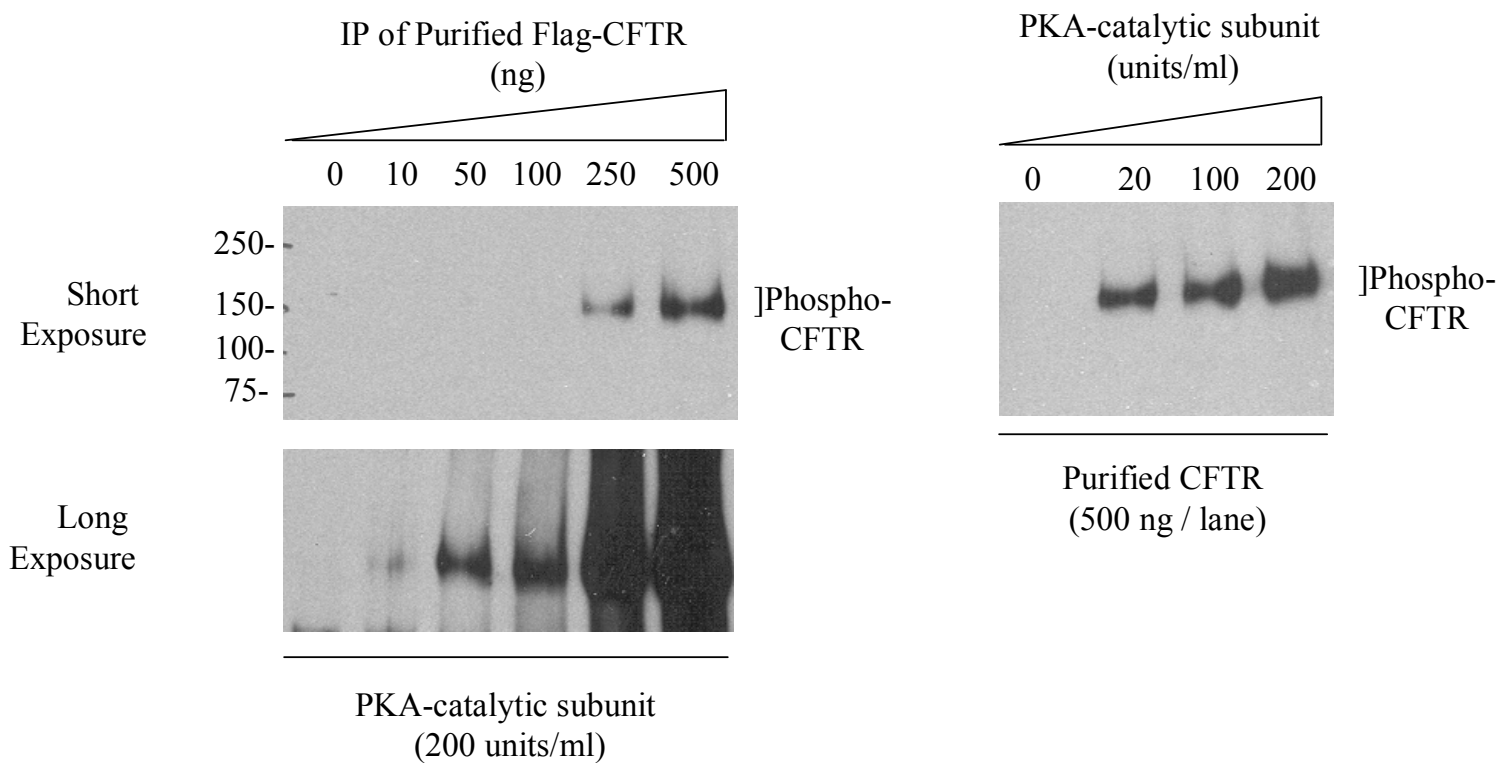

Figure 3-10. Phospho-PKA Substrate Antibody Recognizes CFTR 
Input (1.5\%)
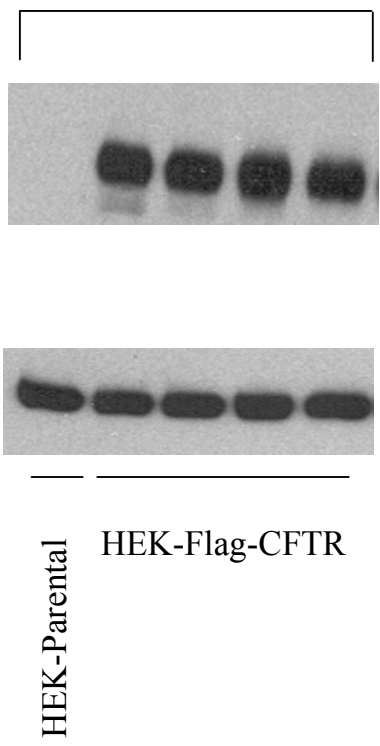

]CFTR/R1104 IgG

]HSP90/F8mab

Input (1.5\%)

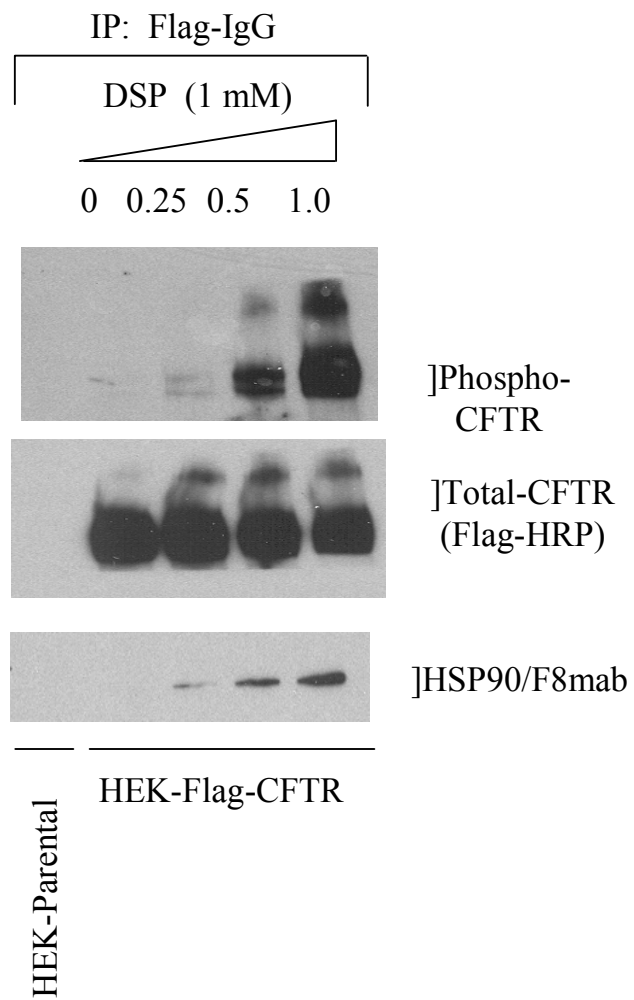

Figure 3-11. Hsp90 Association Increases CFTR Phosphorylation 
(Figure 3-12). This suggests that HSP-90 may play a functional role in the regulation of CFTRs activity. 


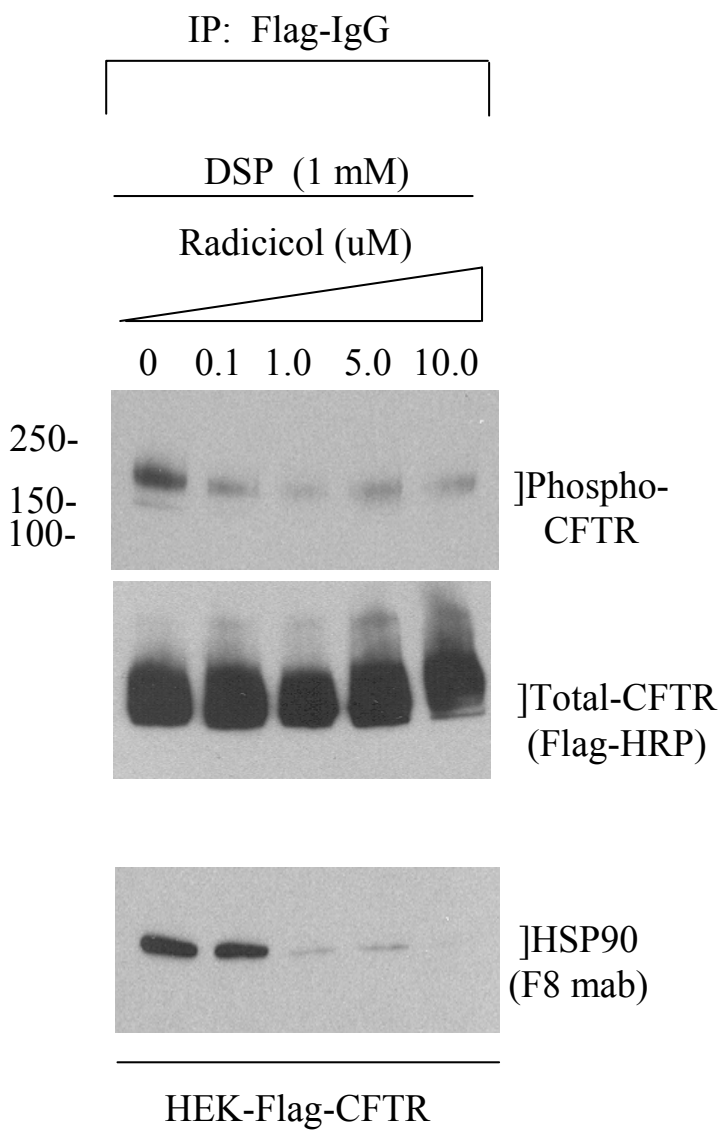

Figure 3-12. Radicicol Inhibits CFTR Association with Hsp90 and CFTR Phosphorylation 


\section{CHAPTER 4: GENERAL DISCUSSION}

\section{Summary of Results}

To date most of the studies of CFTR and Hsp90 have focused on the regulation of CFTR trafficking from the ER to the plasma membrane. The involvement of Hsp90 in regulation of channel function is poorly understood. Earlier studies by this laboratory indicate that CFTR exists in a macromolecular complex with other many other regulatory proteins (Li and Naren 2005).

In this study, the hypothesis that a functionally relevant association exists between CFTR and Hsp90 was tested. We found that the HEK-293 Flag-CFTR cells used in this study allows for a high degree of protein purification in quantities sufficient for mass spectroscopy. An approximately $170 \mathrm{kDa}$ band could be detected with CFTR specific antibodies. This is what we expected as unlabeled CFTR is approximately 168 kDa. The HEK-293 Flag-CFTR cells also show increased protein expression levels above that observed in BHK cells transfected with wild-type (WT)-CFTR and CFTRHis10. The Flag-CFTR expression was shown to be functional using a standard iodide efflux assay. The HEK-293 Flag-CFTR cells responded to agonists known to stimulate various CFTR expressing cell lines (forskolin, IBMX, cpt.cAMP, isoproterenol,

and adenosine). Furthermore, these cells express sufficient quantities of protein to allow for mass spectrometric analysis, which has proven difficult in other cell lines. Thus, this cell line is a valuable tool for the biochemical and functional characterization of CFTR and should prove useful for future studies assessing protein-protein interactions as they relate to CFTR. 
Using affinity cross-linking reagents (DSP \& DPDPB), Hsp-90 is shown to be in association with CFTR in stably transfected HEK-293 cells. Hsp90 associates with CFTR under these conditions more prominently than does Hsp70. The amount of Hsp90 in the macromolecular complex with CFTR is sufficient for mass spectrometry identification. An in vitro assay for CFTR transport function (Ussing Chamber) shows that inhibition of Hsp90 with radicicol, an Hsp90 inhibitor with nanomolar affinity, decreases CFTR mediated $\mathrm{Cl}^{-}$transport. Preliminary in vivo airway fluid clearance studies in mice also show that radicicol inhibits fluid transport, known to require CFTR. Also, Hsp90 protein increases the two-electrode voltage clamp current measured from Xenopus oocytes expressing CFTR chloride channels. When assessing the phosphorylation status of CFTR, it is seen that under conditions that increase the association of Hsp90, there is also observed an increase in the phosphorylation of CFTR. Conversely, in the presence of increasing concentrations of radicicol, both the Hsp90 association CFTR and the phosphorylation of CFTR tend to decrease.

\section{Discussion and Conclusion}

One concern raised in this study is that the association we are seeing may be due to the fact that Flag-CFTR is over-expressed in the HEK-293 cells. This seems not to be the case for several reasons. First, if the association seen with Flag-CFTR were merely due to an artifact of over-expression, than one would predict that in cells that express normal levels of CFTR, the interaction would not exist. However, that is not what we see. In the Calu-3 cells that endogenously express CFTR, Hsp90 can be cross-linked and immunoprecipitated using protein A/G beads conjugated to FTR antibody. Furthermore, 
it is predicted that if the effect is merely due to an artifact of over-expression, than Hsp90 inhibitors should not have an effect on CFTR function. Yet, in Calu-3 cells grown on permeable supports and mounted in Ussing chambers, inhibition of Hsp90 decreases CFTR dependent chloride transport compare to non-treated controls. Furthermore, in C57BL/6 mice which express endogenous levels of CFTR, inhibition of Hsp90 decreases airway fluid clearance. Taken together, these data suggest that the association seen between Hsp90 and CFTR in HEK-Flag-CFTR cells is a real interaction and not merely an artifact of over-expression.

Another concern raised is whether or not the insertion of the 8 amino-acid flag tag is creating a non-functional CFTR protein. This seems not to be the case for several reasons. First, it has been published that the insertions of the Flag-Tag in the $4^{\text {th }}$ outer loop of CFTR preserves the normal biophysical properties of the channel (Schultz, Takahashi et al. 1997). Second, the HEK-Flag-CFTR cells respond to agonists known to activate CFTR such as isoproterenol and adenosine. The very nature of theses agonists require that the Gs protein coupled signaling pathway be functioning in order to get a functional response from CFTR. Therefore, it can be assumed that proteins such as PKA that are required for CFTR function are interacting with the cytosolic domains of the protein. Third, we do in fact observe phosphorylation of Flag-CFTR by cPKA. Taken together, these data suggest that the HEK-Flag-CFTR cells express CFTR protein that functions normally and can interact with cytosolic proteins as required to ensure regulation of channel function.

At present we do not know how Hsp90 is regulating CFTR through PKA. One interesting interpretation of the results is that Hsp90 is interacting directly with CFTR. 
This is certainly possible as many proteins interacting with CFTR to regulate and coordinate overall cellular function (Guggino and Stanton 2006). Another interesting possibility is that Hsp90 may be regulating CFTR through an indirect interaction. Hsp90 is known act as a point of interaction with various signal transduction cascades (Citri, Harari et al. 2006). Thus, it is possible that may Hsp90 may bind directly to PKA and regulate its interaction with the R domain of CFTR (Rich, Berger et al. 1993) (Figure $4-1)$.

Further experimentation will help elucidate the mechanism behind Hsp90 regulation of CFTR. It should be possible to extend our results in the Ussing chamber system in other cells that express CFTR such as primary cultures of alveolar Type II epithelial cells and 16HBE cells. This will allow us to monitor the effect of Hsp90 inhibitors in primary cells and another endogenously expressing cell line in addition to Calu-3. Also, in these experiments we can look at the effect of knocking down Hsp90 expression with SiRNA. Alveolar Type II cells isolated from CF-knockout mice can be used as negative controls in these experiments.

Also, we can determine if $\mathrm{Hsp} 90$ can be physically cross-linked to in vitro and in vivo to further establish that the effect we are seeing is not due to an artifact of overexpression. For the in vitro experiments we can use native lung epithelial cells such as alveolar Type II cells and 16HBE cells. For the in vivo experiments, we can use wildtype and CF- mice. We can also look at the effect of inhibitors of PKA on interaction of Hsp90s and CFTR.

Furthermore, it will also be important to establish where in the cellular environment the interaction of Hsp90, PKA, and CFTR is taking place. This can be done 


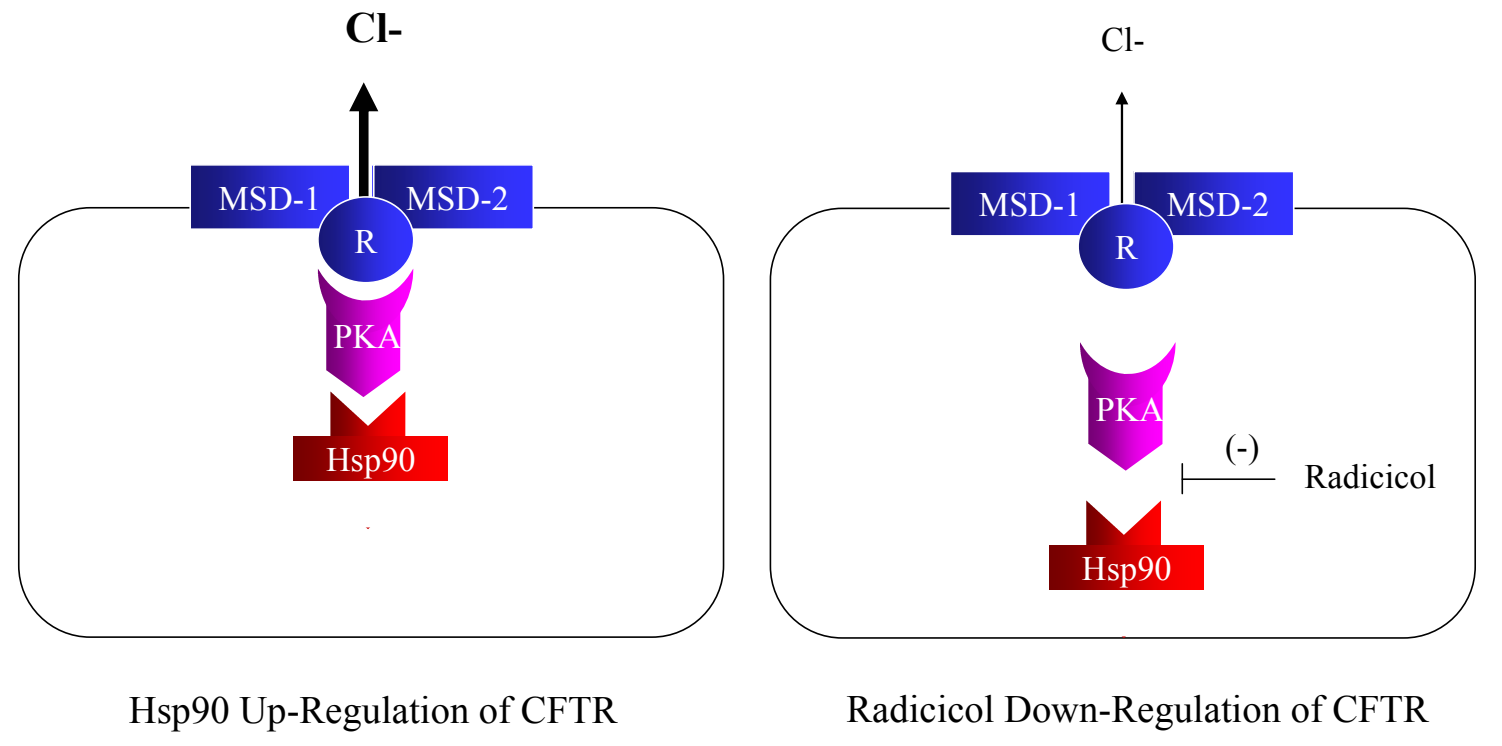

Figure 4-1. Model of CFTR Interaction with Hsp90 
first by biotinylating the surface CFTR using a cell-impermeant biotinylating reagent. This will allow us to determine if the surface pool of CFTR exists in a higher molecular weight complex with Hsp90. Second, we can use Fluorescence Resonance Energy Transfer (FRET) to determine of Hsp90, CFTR and PKA are interacting at the surface of the plasma membrane or if Hsp90 is regulating the endocytic recycling of CFTR. In these experiments, we will also be able to look at the effect of inhibitors of PKA and Hsp90.

In summary, we have observed that Hsp90 associates with CFTR in a manor that suggests it is playing a functional role in the regulation of CFTR. The present biochemical data indicate that this interaction is regulating CFTR though its phosphorylation by PKA. The involvement of Hsp90 in the regulation of CFTR may provide a physiological mechanism for adapting to the metabolic state of the cell, as both CFTR and Hsp90 are dependent upon ATP for their function. It is shown here that inhibitors of Hsp90 can reduce airway fluid clearance. Theses results warrant further investigation into the role of CFTR and Hsp90 in diseases of impaired airway fluid clearance such as edema. Such results could even be of benefit to cancer patients undergoing treatment with Hsp90 inhibitors that experience symptoms (such as grade 3 pancreatitis, shortness of breath, and gastrointestional side effects) that could be explained by a decrease in CFTR function. 


\section{LIST OF REFERENCES}

Abraham, G., C. Kottke, et al. (2003). "Pharmacological and biochemical characterization of the beta-adrenergic signal transduction pathway in different segments of the respiratory tract." Biochem Pharmacol 66(6): 1067-81.

Anderson, D. H. (1938). "Cystic Fibrosis of the pancreas and its relation to celiac disease: A clinical and pathological study." Am J Dis Child 56: 344.

Anderson, M. P., R. J. Gregory, et al. (1991). "Demonstration that CFTR is a chloride channel by alteration of its anion selectivity." Science 253(5016): 202-5.

Anderson, M. P., D. P. Rich, et al. (1991). "Generation of cAMP-activated chloride currents by expression of CFTR." Science 251 (4994): 679-82.

Ashbaugh, D. G., D. B. Bigelow, et al. (1967). "Acute respiratory distress in adults." Lancet 2(7511): 319-23.

Atlas, A. B., S. R. Orenstein, et al. (1992). "Pancreatitis in young children with cystic fibrosis." J Pediatr 120(5): 756-9.

Bear, C. E., C. H. Li, et al. (1992). "Purification and functional reconstitution of the cystic fibrosis transmembrane conductance regulator (CFTR)." Cell 68(4): 80918.

Boat, T. F., M. J. Welsh, et al. (2001). Cystic Fibrosis. New York, McGraw-Hill, Inc.

Borst, P. and R. O. Elferink (2002). "Mammalian ABC transporters in health and disease." Annu Rev Biochem 71: 537-92.

Bossi, E., M. S. Fabbrini, et al. (2007). "Exogenous protein expression in Xenopus oocytes: basic procedures." Methods Mol Biol 375: 107-31.

Boucher, R. C., M. J. Stutts, et al. (1986). "Na+ transport in cystic fibrosis respiratory epithelia. Abnormal basal rate and response to adenylate cyclase activation." $\underline{\mathrm{J}}$ Clin Invest 78(5): 1245-52.

Brone, B. and J. Eggermont (2005). "PDZ proteins retain and regulate membrane transporters in polarized epithelial cell membranes." Am J Physiol Cell Physiol 288(1): C20-9.

Cahill, P., M. W. Nason, Jr., et al. (2000). "Identification of the cystic fibrosis transmembrane conductance regulator domains that are important for interactions with ROMK2." J Biol Chem 275(22): 16697-701.

Cantiello, H. F. (1996). "Role of the actin cytoskeleton in the regulation of the cystic fibrosis transmembrane conductance regulator." Exp Physiol 81(3): 505-14.

Chan, K. W., L. Csanady, et al. (2000). "Severed molecules functionally define the boundaries of the cystic fibrosis transmembrane conductance regulator's $\mathrm{NH}(2)-$ terminal nucleotide binding domain." J Gen Physiol 116(2): 163-80.

Chasan, B., N. A. Geisse, et al. (2002). "Evidence for direct interaction between actin and the cystic fibrosis transmembrane conductance regulator." Eur Biophys J 30(8): $617-24$.

Cheng, S. H., R. J. Gregory, et al. (1990). "Defective intracellular transport and processing of CFTR is the molecular basis of most cystic fibrosis." Cell 63(4): $827-34$. 
Cheng, S. H., D. P. Rich, et al. (1991). "Phosphorylation of the R domain by cAMPdependent protein kinase regulates the CFTR chloride channel." Cell 66(5): 102736.

Citri, A., D. Harari, et al. (2006). "Hsp90 recognizes a common surface on client kinases." J Biol Chem 281(20): 14361-9.

Cormet-Boyaka, E., A. Di, et al. (2002). "CFTR chloride channels are regulated by a SNAP-23/syntaxin 1A complex." Proc Natl Acad Sci U S A 99(19): 12477-82.

Davis, P. B. (2006). "Cystic fibrosis since 1938." Am J Respir Crit Care Med 173(5): 475-82.

Denning, G. M., M. P. Anderson, et al. (1992). "Processing of mutant cystic fibrosis transmembrane conductance regulator is temperature-sensitive." Nature 358(6389): 761-4.

Denning, G. M., L. S. Ostedgaard, et al. (1992). "Localization of cystic fibrosis transmembrane conductance regulator in chloride secretory epithelia." $\underline{\mathrm{J} \text { Clin }}$ Invest 89(1): 339-49.

di Sant' Agnese, P. A. and V. S. Hubbard (1984). The Pancreas. New York, ThiemeStratton.

Du, K., M. Sharma, et al. (2005). "The DeltaF508 cystic fibrosis mutation impairs domain-domain interactions and arrests post-translational folding of CFTR." $\underline{\text { Nat }}$ Struct Mol Biol 12(1): 17-25.

Engelhardt, J. F., J. R. Yankaskas, et al. (1992). "Submucosal glands are the predominant site of CFTR expression in the human bronchus." Nat Genet 2(3): 240-8.

Engelhardt, J. F., M. Zepeda, et al. (1994). "Expression of the cystic fibrosis gene in adult human lung." J Clin Invest 93(2): 737-49.

Factor, P., G. M. Mutlu, et al. (2007). "Adenosine regulation of alveolar fluid clearance." Proc Natl Acad Sci U S A 104(10): 4083-8.

Fang, X., N. Fukuda, et al. (2002). "Novel role for CFTR in fluid absorption from the distal airspaces of the lung." J Gen Physiol 119(2): 199-207.

Fang, X., Y. Song, et al. (2006). "Contribution of CFTR to apical-basolateral fluid transport in cultured human alveolar epithelial type II cells." Am J Physiol Lung Cell Mol Physiol 290(2): L242-9.

Farber, S. (1945). "Some organic digestive disturbances in early life." J Mich Med Soc 44: 587.

Gadgil, H. S., K. M. Pabst, et al. (2003). "Proteome of monocytes primed with lipopolysaccharide: analysis of the abundant proteins." Proteomics 3(9): 1767-80.

Gadsby, D. C., P. Vergani, et al. (2006). "The ABC protein turned chloride channel whose failure causes cystic fibrosis." Nature 440(7083): 477-83.

Goss, C. H., R. G. Brower, et al. (2003). "Incidence of acute lung injury in the United States." Crit Care Med 31(6): 1607-11.

Guggino, W. B. (2004). "The cystic fibrosis transmembrane regulator forms macromolecular complexes with PDZ domain scaffold proteins." Proc Am Thorac Soc 1(1): 28-32.

Guggino, W. B. and B. A. Stanton (2006). "New insights into cystic fibrosis: molecular switches that regulate CFTR." Nat Rev Mol Cell Biol 7(6): 426-36. 
Guidot, D. M., H. G. Folkesson, et al. (2006). "Integrating acute lung injury and regulation of alveolar fluid clearance." Am J Physiol Lung Cell Mol Physiol 291(3): L301-6.

Gurdon, J. B., C. D. Lane, et al. (1971). "Use of frog eggs and oocytes for the study of messenger RNA and its translation in living cells." Nature 233(5316): 177-82.

Haws, C., W. E. Finkbeiner, et al. (1994). "CFTR in Calu-3 human airway cells: channel properties and role in cAMP-activated Cl- conductance." Am J Physiol 266(5 Pt 1): L502-12.

Hegedus, T., T. Sessler, et al. (2003). "C-terminal phosphorylation of MRP2 modulates its interaction with PDZ proteins." Biochem Biophys Res Commun 302(3): 45461.

Hinzpeter, A., J. Lipecka, et al. (2006). "Association between Hsp90 and the ClC-2 chloride channel upregulates channel function." Am J Physiol Cell Physiol 290(1): C45-56.

Jakob, U., H. Lilie, et al. (1995). "Transient interaction of Hsp90 with early unfolding intermediates of citrate synthase. Implications for heat shock in vivo." J Biol Chem 270(13): 7288-94.

Jentsch, T. J., M. Poet, et al. (2005). "Physiological functions of CLC Cl- channels gleaned from human genetic disease and mouse models." Annu Rev Physiol 67: 779-807.

Jiang, X., D. H. Ingbar, et al. (1998). "Adrenergic stimulation of $\mathrm{Na}+$ transport across alveolar epithelial cells involves activation of apical Cl- channels." Am J Physiol 275(6 Pt 1): C1610-20.

Jiang, X., D. H. Ingbar, et al. (2001). "Adrenergic regulation of ion transport across adult alveolar epithelial cells: effects on Cl- channel activation and transport function in cultures with an apical air interface." J Membr Biol 181(3): 195-204.

Kerem, B., J. M. Rommens, et al. (1989). "Identification of the cystic fibrosis gene: genetic analysis." Science 245(4922): 1073-80.

Knowles, M., J. Gatzy, et al. (1981). "Increased bioelectric potential difference across respiratory epithelia in cystic fibrosis." N Engl J Med 305(25): 1489-95.

Knowles, M. R., M. J. Stutts, et al. (1983). "Abnormal ion permeation through cystic fibrosis respiratory epithelium." Science 221(4615): 1067-70.

Lee, M. G., W. C. Wigley, et al. (1999). "Regulation of Cl-/ HCO3- exchange by cystic fibrosis transmembrane conductance regulator expressed in NIH 3T3 and HEK 293 cells." J Biol Chem 274(6): 3414-21.

Li, C., K. S. Dandridge, et al. (2005). "Lysophosphatidic acid inhibits cholera toxininduced secretory diarrhea through CFTR-dependent protein interactions." J Exp Med 202(7): 975-86.

Li, C. and A. P. Naren (2005). "Macromolecular complexes of cystic fibrosis transmembrane conductance regulator and its interacting partners." Pharmacol Ther 108(2): 208-23.

Li, C., K. Roy, et al. (2004). "Molecular assembly of cystic fibrosis transmembrane conductance regulator in plasma membrane." J Biol Chem 279(23): 24673-84.

Lohi, H., G. Lamprecht, et al. (2003). "Isoforms of SLC26A6 mediate anion transport and have functional PDZ interaction domains." Am J Physiol Cell Physiol 284(3): C769-79. 
Loo, M. A., T. J. Jensen, et al. (1998). "Perturbation of Hsp90 interaction with nascent CFTR prevents its maturation and accelerates its degradation by the proteasome." Embo J 17(23): 6879-87.

Lowe, C. U., C. D. May, et al. (1949). "Fibrosis of the pancreas in infants and children: a stastical study of clinical and hereditary features." Am J Dis Child 78: 349-74.

Lukacs, G. L., X. B. Chang, et al. (1993). "The delta F508 mutation decreases the stability of cystic fibrosis transmembrane conductance regulator in the plasma membrane. Determination of functional half-lives on transfected cells." J Biol Chem 268(29): 21592-8.

Marino, C. R., L. M. Matovcik, et al. (1991). "Localization of the cystic fibrosis transmembrane conductance regulator in pancreas." J Clin Invest 88(2): 712-6.

Matthay, M. A., H. G. Folkesson, et al. (2002). "Lung epithelial fluid transport and the resolution of pulmonary edema." Physiol Rev 82(3): 569-600.

Matthay, M. A., L. Robriquet, et al. (2005). "Alveolar epithelium: role in lung fluid balance and acute lung injury." Proc Am Thorac Soc 2(3): 206-13.

McCarty, N. A., S. McDonough, et al. (1993). "Voltage-dependent block of the cystic fibrosis transmembrane conductance regulator $\mathrm{Cl}$ - channel by two closely related arylaminobenzoates." J Gen Physiol 102(1): 1-23.

McCarty, N. A. and Z. R. Zhang (2001). "Identification of a region of strong discrimination in the pore of CFTR." Am J Physiol Lung Cell Mol Physiol 281(4): L852-67.

McNicholas, C. M., W. B. Guggino, et al. (1996). "Sensitivity of a renal K+ channel (ROMK2) to the inhibitory sulfonylurea compound glibenclamide is enhanced by coexpression with the ATP-binding cassette transporter cystic fibrosis transmembrane regulator." Proc Natl Acad Sci U S A 93(15): 8083-8.

McNicholas, C. M., M. W. Nason, Jr., et al. (1997). "A functional CFTR-NBF1 is required for ROMK2-CFTR interaction." Am J Physiol 273(5 Pt 2): F843-8.

Mutlu, G. M., Y. Adir, et al. (2005). "Interdependency of beta-adrenergic receptors and CFTR in regulation of alveolar active Na+ transport." Circ Res 96(9): 999-1005.

Mutlu, G. M., W. J. Koch, et al. (2004). "Alveolar epithelial beta 2-adrenergic receptors: their role in regulation of alveolar active sodium transport." Am J Respir Crit Care Med 170(12): 1270-5.

Mutlu, G. M. and J. I. Sznajder (2005). "Mechanisms of pulmonary edema clearance." Am J Physiol Lung Cell Mol Physiol 289(5): L685-95.

Naldini, L., U. Blomer, et al. (1996). "In vivo gene delivery and stable transduction of nondividing cells by a lentiviral vector." Science 272(5259): 263-7.

Naren, A. P., B. Cobb, et al. (2003). "A macromolecular complex of beta 2 adrenergic receptor, CFTR, and ezrin/radixin/moesin-binding phosphoprotein 50 is regulated by PKA." Proc Natl Acad Sci U S A 100(1): 342-6.

Naren, A. P., D. J. Nelson, et al. (1997). "Regulation of CFTR chloride channels by syntaxin and Munc18 isoforms." Nature 390(6657): 302-5.

Naren, A. P., M. W. Quick, et al. (1998). "Syntaxin 1A inhibits CFTR chloride channels by means of domain-specific protein-protein interactions." Proc Natl Acad Sci U S A 95(18): 10972-7.

Pappin, D. J., P. Hojrup, et al. (1993). "Rapid identification of proteins by peptide-mass fingerprinting." Curr Biol 3(6): 327-32. 
Peters, K. W., J. Qi, et al. (1999). "Syntaxin 1A inhibits regulated CFTR trafficking in xenopus oocytes." Am J Physiol 277(1 Pt 1): C174-80.

Prat, A. G., C. C. Cunningham, et al. (1999). "Actin filament organization is required for proper cAMP-dependent activation of CFTR." Am J Physiol 277(6 Pt 1): C11609.

Prat, A. G., Y. F. Xiao, et al. (1995). "cAMP-independent regulation of CFTR by the actin cytoskeleton." Am J Physiol 268(6 Pt 1): C1552-61.

Prodromou, C., S. M. Roe, et al. (1997). "Identification and structural characterization of the ATP/ADP-binding site in the Hsp90 molecular chaperone." Cell 90(1): 65-75.

Quinton, P. M. (1986). "Missing Cl conductance in cystic fibrosis." Am J Physiol 251(4 Pt 1): C649-52.

Quinton, P. M. and J. Bijman (1983). "Higher bioelectric potentials due to decreased chloride absorption in the sweat glands of patients with cystic fibrosis." N Engl J Med 308(20): 1185-9.

Reddy, M. M., M. J. Light, et al. (1999). "Activation of the epithelial Na+ channel $(\mathrm{ENaC})$ requires CFTR Cl- channel function." Nature 402(6759): 301-4.

Rich, D. P., H. A. Berger, et al. (1993). "Regulation of the cystic fibrosis transmembrane conductance regulator $\mathrm{Cl}$ - channel by negative charge in the $\mathrm{R}$ domain." J Biol Chem 268(27): 20259-67.

Riordan, J. R., J. M. Rommens, et al. (1989). "Identification of the cystic fibrosis gene: cloning and characterization of complementary DNA." Science 245(4922): 106673.

Roe, S. M., C. Prodromou, et al. (1999). "Structural basis for inhibition of the Hsp90 molecular chaperone by the antitumor antibiotics radicicol and geldanamycin." J Med Chem 42(2): 260-6.

Rommens, J. M., M. C. Iannuzzi, et al. (1989). "Identification of the cystic fibrosis gene: chromosome walking and jumping." Science 245(4922): 1059-65.

Rowe, S. M., S. Miller, et al. (2005). "Cystic fibrosis." N Engl J Med 352(19): 19922001

Sartori, C. and M. A. Matthay (2002). "Alveolar epithelial fluid transport in acute lung injury: new insights." Eur Respir J 20(5): 1299-313.

Schreiber, R., R. Nitschke, et al. (1999). "The cystic fibrosis transmembrane conductance regulator activates aquaporin 3 in airway epithelial cells." J Biol Chem 274(17): 11811-6.

Schultz, B. D., A. Takahashi, et al. (1997). "FLAG epitope positioned in an external loop preserves normal biophysical properties of CFTR." Am J Physiol 273(6 Pt 1): C2080-9.

Shenolikar, S., J. W. Voltz, et al. (2004). "Regulation of ion transport by the NHERF family of PDZ proteins." Physiology (Bethesda) 19: 362-9.

Short, D. B., K. W. Trotter, et al. (1998). "An apical PDZ protein anchors the cystic fibrosis transmembrane conductance regulator to the cytoskeleton." J Biol Chem 273(31): 19797-801.

Staub, N. C. (1974). "Pulmonary edema." Physiol Rev 54(3): 678-811.

Stutts, M. J., C. M. Canessa, et al. (1995). "CFTR as a cAMP-dependent regulator of sodium channels." Science 269(5225): 847-50. 
Sun, F., M. J. Hug, et al. (2000). "E3KARP mediates the association of ezrin and protein kinase A with the cystic fibrosis transmembrane conductance regulator in airway cells." J Biol Chem 275(38): 29539-46.

Taussig, L. M. (1984). An overview. New York, Thieme-Stratton.

Taussig, L. M., C. C. Lobeck, et al. (1972). "Fertility in males with cystic fibrosis." N Engl J Med 287(12): 586-9.

Thelin, W. R., C. A. Hodson, et al. (2005). "Beyond the brush border: NHERF4 blazes new NHERF turf." J Physiol 567(Pt 1): 13-9.

Thomas, P. J., P. Shenbagamurthi, et al. (1992). "The cystic fibrosis transmembrane conductance regulator. Effects of the most common cystic fibrosis-causing mutation on the secondary structure and stability of a synthetic peptide." J Biol Chem 267(9): 5727-30.

Vergani, P., S. W. Lockless, et al. (2005). "CFTR channel opening by ATP-driven tight dimerization of its nucleotide-binding domains." Nature 433(7028): 876-80.

Wang, S., R. W. Raab, et al. (1998). "Peptide binding consensus of the NHE-RF-PDZ1 domain matches the $\mathrm{C}$-terminal sequence of cystic fibrosis transmembrane conductance regulator (CFTR)." FEBS Lett 427(1): 103-8.

Ward, C. L., S. Omura, et al. (1995). "Degradation of CFTR by the ubiquitin-proteasome pathway." Cell 83(1): 121-7.

Ware, L. B. and M. A. Matthay (2001). "Alveolar fluid clearance is impaired in the majority of patients with acute lung injury and the acute respiratory distress syndrome." Am J Respir Crit Care Med 163(6): 1376-83.

Ware, L. B. and M. A. Matthay (2005). "Clinical practice. Acute pulmonary edema." $\underline{N}$ Engl J Med 353(26): 2788-96.

Wheeler, A. P. and G. R. Bernard (2007). "Acute lung injury and the acute respiratory distress syndrome: a clinical review." Lancet 369(9572): 1553-64.

Wu, X., J. K. Wakefield, et al. (2000). "Development of a novel trans-lentiviral vector that affords predictable safety." Mol Ther 2(1): 47-55.

Young, J. C., I. Moarefi, et al. (2001). "Hsp90: a specialized but essential protein-folding tool." J Cell Biol 154(2): 267-73.

Zielenski, J. and L. C. Tsui (1995). "Cystic fibrosis: genotypic and phenotypic variations." Annu Rev Genet 29: 777-807. 


\section{VITA}

Kevin Lee Marrs was born in Waynesboro, Virginia on March 21, 1971. He received a Bachelor of Science degree in Biology from Virginia Tech, Blacksburg, Virginia, in 1993. In 1999, he graduated from The University of Alabama at Birmingham with a M.Sc. degree in Basic Medical Science. In August, 2004 he entered the inaugural class of the Integrated Program in Biomedical Science. At that time, he was also awarded a Health Services Collegiate Program (HSCP) Scholarship from the United States Navy. During the 2005-2006 academic year, he served as President of the Graduate Student Executive Council for the College of Graduate Health Sciences (CGHS). He also served as the President of the Honor Council during the 2006-2007 academic year. Kevin will graduate with Highest Honors in December of 2007. Upon graduation, he will be commissioned as a Lieutenant $(\mathrm{O}-3)$ in the United States Navy. He will report to the Navy Medical Research Center near Bethesda, Maryland. There he will serve as a Research Physiologist in the Department of Undersea Medicine and study the molecular mechanisms underlying decompression sickness. He is married to Jessica Marrs of Hattiesburg, Mississippi and has three daughters; Sarah Kate, Natalie, and Elizabeth. 